\title{
El rol del capital social y de la cultura en el proceso de desarrollo
}

\author{
Kliksberg, Bernardo*
}

\section{Resumen}

En este trabajo se pone en foco un tema relevante del nuevo debate sobre el desarrollo relacionado con las posibilidades que brinda el Capital Social y la Cultura, en la gestión del desarrollo económico y social como una manera de resolver las contradicciones que impiden lograrlo. Se discute sobre la crisis del unnsamiento económico convencional y el replanteo del modelo de desarrollo a través de la inclusión de nuevas variables y las interrelaciones de las distintas dimensiones. El trabajo se centra en el estudio del capital social y la cultura en tres experiencias latinoamericanas: Villa EI Salvador, Las Ferias de Consumo Familiar de Venezuela y el $P$;

'articipativo de Porto Alegre. Se concluye que la cultura, parte relevante del capital social, tiene muchas posibilidades de contribuir al desarrollo y debe ser un fin en si misma para enriquecer espiritual y socialmente a la sociedad.

Palabras clave: Capital social, cultura, desarrollo.

Recibido: $99-09-\overline{23}$. Aceptado: $99-11-06$

* Profesor honorario de la Universidad Nacional de Buenos Aires, Doctor Honoris Causa de la Universidad Nacional Experimental Rafael María Baralt (UNERMB), Profesor Emérito de la Universidad del Congreso, Director del proyecto Regional de las Naciones Unidas para América Latina de "Modernización de Estado y Gerencia Social" (PNUD-CLAD). Actualmente es Coordinador General del Instituto Interamericano de Desarrollo Social (INDES-BID).

Las opiniones expresadas en este trabajo son de responsabilidad del autor y no representan necesariamente las de la institución donde se desempeña. 


\section{The Roles of Social Capital and Culture in the Development Process}

\section{Abstract}

In this paper the focus is on a relevant theme in the new debate on development, related to the possibilities that social capital and culture offer in the management of economic and social development in terms of resolving the contradictions that impede this process. The crisis of conventional economic thought is discussed and a different development model is proposed through the inclusion of new variables and the interrelation of the various dimensions of the same. The paper centers on the study of social capital and culture in three Latin American experiences: Villa El Salvador, the Family Consumer Fairs in Venezuela, and the Participative Municipal Budget of Porto Alegre. The conclusion is that culture, a relevant aspect of social capital, has many possibilities of contributing to development and should be an end in itself in order to spiritually and socially enrich society.

Key words: Social capital, culture, development.

\section{El nuevo debate sobre el desarrollo}

A fines del siglo $X X$ la humanidad cuenta con inmensas fuerzas productivas. Las revoluciones tecnológicas en curso han alterado sustancialmente sus capacidades potenciales de generar bienes y servicios. Los avances simultáneos en campos como la informática, la biotecnología, la robótica, la microelectrónica, las telecomunicaciones, la ciencia de los materiales y otras áreas, han determinado rupturas cualitativas en las posibilidades usuales de producción, ampliándolas extensamente, y con un horizonte de continuo crecimiento hacia adelante. Sin embargo, 1300 millones de personas carecen de lo más mínimo y viven en pobreza extrema con menos de un dólar de ingresos al día, 3000 millones se hallan en pobreza, teniendo que subsistir con menos de dos dólares diarios, 1300 millones de personas carecen de agua potable, 3000 millones no tienen instalaciones sanitarias básicas, y 2000 millones no reciben electricidad.

Alcanzar la deseada meta del desarrollo económico y social es más viable que nunca en términos de tecnologías y potencial productivo pero, al mismo tiempo, el objetivo se halla muy distante de amplias poblaciones en diversos continentes, entre ellos, en América Latina.

La "aldea global" en que se ha convertido el planeta, en donde las interrelaciones entre los países y los mercados se multiplican continuamente, parece carac- 
terizarse por una explosión de complejidad, direcciones contradictorias de evolución, y altas dosis de incertidumbre. Exploradores de las fronteras de las nuevas realidades, como Ylia Prygogine (1988), Premio Nobel de Química, ha señalado que la mayor parte de las estructuras de la realidad actual, son "estructuras disipativas de final abierto", es difícil predecir en qué sentido evolucionarán, y las lógicas tradicionales son impotentes para explicar su curso. Edgar Morín (1991) resalta que en lugar del "fin de la historia", vaticinado por algunos que alegaron que al desaparecer el mundo bipolar, la historia seria previsible y hasta "aburrida", lo que tenemos ante nuestros ojos es que "de aquí en adelante el futuro se llama incertidumbre". La historia en curso está marcada por severas contradicciones. Así, al mismo tiempo, por ejemplo, que el conocimiento tecnológico disponible ha multiplicado las capacidades de dominar la naturaleza, el ser humano está creando desequilibrios ecológicos de gran magnitud, poniendo en peligro aspectos básicos del ecosistema, y su propia supervivencia. Mientras que las capacidades productivas han llevado la pr....... ion muritigl a más de 25 trillones de dólares, las polarizaciones sociales se han incrementando fuertemente y, según los informes de las Naciones Unidas (1998), 358 personas son poseedoras de una riqueza acumula- da superior a la del $45 \%$ de la población mundial. Las disparidades alcanzan los aspectos más elementales de la vida cotidiana. Los acelerados progresos en medicina, han permitido una extensión considerable en la esperanza de vida pero, mientras en las 26 naciones más ricas la misma alcanzaba en 1997, a 78 años de edad, en los 46 países más pobres era, en dicho año, de 53 años.

La idea del progreso indefinido está siendo suplantada por visiones que asignan un rol mayor a las complejidades, las contradicciones, $y$ las incertidumbres $y$ buscan soluciones a partir de integrar las mismas a las perspectivas de análisis de la realidad'.

En este marco general, hay un nuevo debate en activa ebullición en el campo del desarrollo. Buscando caminos más efectivos, en un mundo donde la vida cotidiana de amplios sectores está agobiada por carencias agudas, y donde se estima que una tercera parte de la población activa mundial se halla afectada por serios problemas de desocupación y subocupación, el debate está revisando supuestos no convalidados por los hechos, y abriéndose hacia variables a las que se asignaba escaso peso en las últimas décadas.

Hay una revalorización en el nuevo debate de aspectos no incluidos en el pensamiento económico convencional.

1 Morin resalta las dificultades para tener una visión clara de hacia adónde avanza la historia: "Estamos en lo desconocido, más aún, en lo inominado. Nuestro conocimiento de tiempos actuales se manifiesta solamente en el prefijo sin forma "pos" (posindustrial, posmoderno, posestructuralista), o en el prefijo negativo "ante" (antitotalitario). No podemos dar un rostro a nuestro futuro, ni siquiera a nuestro presente". 
Se ha instalado una potente área de análisis en vertiginoso crecimiento que gira en derredor de la idea de "capital social". Uno de los focos de ese área, a su vez con su propia especificidad, es el reexamen de las relaciones entre cultura y desarrollo. Como señala Lourdes Arizpe (1998), "la cultura ha pasado a ser el último aspecto inexplorado, de los esfuerzos que se despliegan a nivel internacional, para fomentar el desarrollo económico". Enrique V. Iglesias (1997), subraya que se abre en este reexamen de las relaciones entre cultura y desarrollo, un vasto campo de gran potencial. Resalta "hay múltiples aspectos en la cultura de cada pueblo que pueden favorecer a su desarrollo económico y social, es preciso descubrirlos, potenciarlos, y apoyarse en ellos, y hacer esto con seriedad significa replantear la agenda del desarrollo de una manera que a la postre resultará más eficaz, porque tomará en cuenta potencialidades de la realidad que son de su esencia $y$, que hasta ahora, han sido generalmente ignoradas".

Ubicado en este contexto bullente en reclamos por rediscutir la visión convencional del desarrollo, e integrar nuevas dimensiones, este trabajo procura poner a foco un tema relevante del nuevo debate, las posibilidades del capital social y de la cultura, de aportar al desarrollo económico y social. Particularmente, el trabajo se centra en sus posibles contribuciones a América Latina, una región con graves problemas en los campos de la pobreza (afecta a vastos sectores de la población) y de la inequidad (es considerado el Continente más desigual del Planeta). Seguramente la integración de estos planos complejizará aún mucho más la búsqueda de estrategias y diseños adecuados. Pero esa es la idea, las politicas basadas en diseños que marginan aspectos como los mencionados, han demostrado muy profundas limitaciones.

El trabajo se propone cumplir su propósito a través de varios momentos sucesivos de análisis. En primer lugar se presentan aspectos de la crisis del pensamiento económico convencional. La nueva atención prestada a capital social y cultura, se inscribe en esa crisis. En segundo término se explora la idea de capital social. El énfasis se pone, en este caso, no en la discusión teórica, sino en la presencia concreta del mismo en realidades actuales. En tercer término, con apoyo en los desarrollos anteriores, se ingresa a observar "el capital social en acción" en realidades latinoamericanas. Se indaga a través de experiencias concretas de la región, cómo el capital social y la cultura constituyen potentes instrumentos de construcción histórica. Por último, se formulan algunas reflexiones sobre posibles aportes de la cultura al desarrollo latinoamericano.

\section{La crisis del pensamiento económico convencional}

Se hallan en plena actividad, actualmente, diversas líneas de discusión sobre los supuestos económicos que han orientado el desarrollo en las últimas décadas. El debate en curso no aparece como un debate hacia el interior de la academia, en donde diversas escuelas de pensamiento o personalidades defienden determinados enfoque surgidos de su propia especulación. Está fuertemente influido por las dificultades del pensa- 
miento convencional en la realidad. Lo han dinamizado y urgido procesos como los severos problemas experimentados por las economías del Sudeste asiático, las graves crisis observables en economías en transición, como la rusa, las inestabilidades pronunciadas en los mercados financieros internacionales, los desajustes y las polarizaciones sociales en regiones como América Latina, y otras. Aparece gracias a los importantes avances en la medición de los fenómenos económicos y sociales, como un debate donde la especulación infinita a partir de las propias premisas, característica de décadas anteriores, es reemplazado por análisis que arrancan de la vasta evidencia empírica que está generando el instrumental cuantitativo y estadístico.

Una primera característica de la crisis en curso es el llamado, cada vez más amplio, a respetar la complejidad de la realidad. Se previene contra la "soberbia epistemológica" conque el pensamiento económico convencional trabajó múltiples problemas, pretendiendo capturarles y resolverlos a partir de marcos de referencia basados en grupos de variables limitadas, de índole casi exclusivamente económico, que no dejaban espacio a variables de otras procedencias. Joseph Stiglitz (1998a) reclama que "un principio del consenso emergente es que un mayor grado de humildad es necesario". Aboga por un nuevo consenso, post Washington, ante las dificultades surgidas en la realidad. Señala a América Latina como uno de los casos que evidencia las dificultades. Afirma: "yo argumentaría que la experiencia latinoamericana sugiere que deberiamos reexaminar, rehacer y ampliar, los conocimientos acerca de la economía de desarrollo que se toman como verdad, mientras planificamos la próxima serie de reformas".

Otro aspecto sobresaliente de la nueva discusión sobre el desarrollo, es la apelación cada vez más generalizada a superar los enfoques reduccionistas y buscar, para captar la complejidad, perspectivas integradoras de variables múltiples. Enrique Iglesias (1997) advierte: "EI desarrollo sólo puede encararse en forma integral; los entoques monistas sencillamente no funcionan". Joseph Stiglitz (1998b) destaca que se ha visto al desarrollo como un "problema técnico que requiere soluciones técnicas", y esa visión ha chocado con la realidad que va mucho mas allá de ella. Señala que "un evento definidor ha sido que muchos países han seguido los dictados de liberalización, estabilización y privatización, las premisas centrales del llamado Consenso de Washington y, sin embargo, no han crecido. Las soluciones técnicas no son evidentemente suficientes".

Un tema resaltante de la discusión abierta es el énfasis en no confundir los medios con los fines, desvío en el que se sugiere, se ha caído con frecuencia. Los objetivos finales del desarrollo tienen que ver con la ampliación de las oportunidades reales de los seres humanos, de desenvolver sus potencialidades. Una sociedad progresa efectivamente cuando los indicadores clave como años que la gente vive, calidad de su vida, y desarrollo de su potencial avanzan. Las metas técnicas son absolutamente respetables y relevantes, pero son medios al servicio de esos objetivos finalistas. Si se produce un proceso de sustitución silenciosa de los fines reales por los medios, se puede 
perder de vista el horizonte hacia el cual se debería avanzar, y equivocar los métodos para medir el avance. La elevación del Producto Bruto per capita, por ejemplo, aparece en la nueva perspectiva como un objetivo importante y deseable, pero sin dejar de tener nunca en cuenta que es un medio al servicio de fines mayores, como los índices de nutrición, salud, educación, libertad, y otros. Sus mediciones no reflejan por tanto, necesariamente, lo que está sucediendo en relación a dichas metas. Amartya Sen (1998) analiza detalladamente esta visión general en el caso de los recursos humanos. Señala que constituye un progreso considerable el nuevo énfasis puesto en los mismos, pero que debe entenderse que el ser humano no es sólo un medio del desarrollo, sino, su fin último. Esa visión no debe perderse de vista. Subraya "Si en última instancia considerásemos al desarrollo como la ampliación de la capacidad de la población para realizar actividades elegidas libremente y valoradas, sería del todo inapropiado ensalzar a los seres humanos como "instrumentos del desarrollo económico. Hay una gran diferencia entre los medios y los fines".

Stiglitz (1998b) enfatiza que la confusión medios-fines ha sido frecuente en la aplicación del Consenso de Washington: "se ha tomado la privatización y la liberalización comercial como fines en sí mismos más que como medios para alcanzar un crecimiento sostenible, equitativo y democrático. Se ha focalizado demasiado en la estabilidad de los precios, más que en el crecimiento y la estabilidad de la producción. Se ha fallado en reconocer que el fortalecimiento de las instituciones financieras es tan importante para la estabilidad económica, como controlar el déficit presupuestario y aumentar la oferta de dinero. Se ha centrado en la privatización, pero se ha puesto muy poca atención a la infraestructura institucional, que es necesaria para hacer que los mercados funcionen $y$, especialmente, a la importancia de la competición.

A partir de estas percepciones sobre la estrechez del enfoque meramente técnico y la necesidad de delimitar fines y medios, se plantean visiones ampliatorias de los objetivos que debería perseguir el desarrollo. Junto al crecimiento económico, surge la necesidad de lograr desarrollo social, mejorar la equidad, fortalecer la democracia, y preservar los equilibrios medioambientales. El Consenso de los Presidentes de América en Santiago (1998), reflejó este orden de preocupaciones incluyendo, en su plan de acción, puntos que exceden a los abordajes convencionales como, entre otros: el énfasis en la promoción de la educación, la preservación y profundización de la democracia, la justicia y los derechos humanos, la lucha contra la pobreza y la discriminación, el fortalecimiento de los mercados financieros, y la cooperación regional en asuntos ambientales.

Se resalta en las críticas al pensamiento económico convencional como las limitaciones de su marco de análisis, han creado serias insuficiencias de operación. Variables excluidas o marginadas como, entre otras, las políticas, y las institucionales, tienen alto peso en la realidad $y$ van a incidir fuertemente creando escenarios no previstos. Quejarse de ellas como "intrusos indeseables" no conduce a ningún camino útil. Pareciera que lo que 
corresponde no es reclamarle a la realidad, sino revisar el esquema conceptual con el que se está analizando, para darles su debido lugar.

Alessina y Peroti (1994), entre otros, plantean la necesidad de ingresar en un examen en profundidad de las intersecciones entre política y economía. Destacan: "... la economía sola no puede explicar integralmente la enorme variabilidad entre los países en el crecimiento y más generalmente los resultados económicos y las alternativas de política. Las elecciones de políticas económicas no son hechas por planificadores sociales que viven sólo entre documentos académicos. Más bien, la política económica es el resultado de luchas polfticas dentro de estructuras institucionales".

Sen (1981) analiza, al respecto, cómo las realidades políticas son determinantes en las hambrunas masivas que han afligido a amplios grupos humanos en el presente siglo. Según sus investigaciones (1981), las hambrunas no tienen que ver necesariamente con escaseces de recursos alimenticios. Se vinculan más con factores como las disparidades de precios relativos, los bajos salarios, y las maniobras especulatorias. El cuadro de condiciones políticas pesa fuertemente al respecto. Examinando las correlaciones entre hambrunas masivas y tipo de régímen político, Sen (1998) determina que "ningún país dotado de un sistema de elecciones multipartidistas, con partidos de oposición capaces de expresarse como tales, de una prensa capacitada para informar y poner en tela de juicio la política gubernamental sin temor a ser censurada, ha sido escenario de hambrunas realmente importantes". En esos paises funcionan poderosos "incentivos políticos" para que se tomen decisiones que eviten la hambruna. En cambio, observa que las hambrunas de mayores proporciones han tenido lugar en: "territorios colonizados y gobernados por autoridades imperialistas extranjeras, dictaduras militares de corte moderno, bajo el control de potentados autoritarios, - regímenes de partido único donde no se tolera la disidencia política".

"Las instituciones cuentan", es el título de un reciente trabajo del Banco Mundial (1998) sobre la materia. En el mismo, desarrolla en detalle la visión de que todo el tema de las instituciones debe ser incorporado al análisis de las realidades económicas y el diseño de políticas. Entiende, como tales, al conjunto de reglas formales e informales y sus mecanismos de ejecución que inciden sobre el comportamiento de los individuos y las organizaciones de una sociedad. Entre las formales se hallan las constituciones, leyes, regulaciones, contratos, etc. Entre las informales están la ética, la confianza, los preceptos religiosos y otros códigos implícitos. Una de las debilidades del Consenso de Washington habría sido, según el Banco Mundial, la no inclusión de las mismas entre las políticas que recomienda. Señala al respecto: "Con una sola excepción (la protección de los derechos de propiedad), las prescripciones de política del Consenso de Washington ignoran el rol potencial que los cambios en las instituciones pueden jugar en acelerar el desarrollo económico y social". Un amplio número de investigaciones recientes da cuenta de correlaciones estadísticas significativas entre buen funcionamiento de instituciones básicas, como los meca- 
nismos anticorrupción, la calidad de las instituciones públicas, la credibilidad, y otras, y los avances en crecimiento, desarrollo social y equidad.

En las reformulaciones en curso del pensamiento económico convencional ha ingresado, como un tema central, el del capital humano. Mejorar el perfil de la población de un país es un fin en si mismo, como resaltaba Sen. Al mismo tiempo, constituye una via fundamental para alcanzar productividad, progreso tecnológico y competitividad en los escenarios económicos de fin de siglo. En ellos el papel del capital humano en la producción es decisivo. En estructuras productivas, cada vez más basadas en conocimiento, como las presentes y prospectivas, los niveles de calificación promedio de una sociedad van a ser determinantes en sus posibilidades de generar, absorber y difundir tecnologías avanzadas. La educación hace una diferencia crucial según las mediciones disponibles, tanto para la vida de las personas, el desenvolvimiento de las familias, la productividad de las empresas, y los resultados económicos macro de un país. Es, como se la ha denominado, una estrategia "ganadora" con beneficios para todos. La nutrición y la salud son a su vez, desde ya, condiciones de base para el desenvolvimiento del capital humano.

En este cuadro de conjunto, donde las dificultades de la realidad han impulsado una crisis y un proceso de reenfoque profundo del pensamiento económi$c o$, se inscribe la integración activa a los análisis del capital social y de la cultura. Una ola de investigaciones de los últimos años indica, con datos de campo a su favor, cómo diversos componentes no visi- bles del funcionamiento cotidiano de una sociedad, que tienen que ver con la situación de su tejido social básico, inciden silenciosamente en las posibilidades de crecimiento y desarrollo. Denominados capital social, los exploraremos en la sección siguiente. Empiezan a influir en el diseño de politicas en algunos países avanzados, han comenzado a formar parte de la elaboración de los proyectos de desarrollo, e instituciones de cooperación internacional, están incluyendo los progresos en capital social, en los criterios de medición del grado de éxito de los proyectos.

Al centro del capital social se hallan múltiples elementos del campo de la cultura. Como lo destaca Arizpe (1998), tienen todo orden de implicancias prácticas y han sido marginados por el pensamiento convencional. Destaca: "La teoría y la política del desarrollo deben incorporar los conceptos de cooperación, confianza, etnicidad, identidad, comunidad y amistad, ya que estos elementos constituyen el tejido social en que se basan la política y la economía. En muchos lugares, el enfoque limitado del mercado basado en la competencia y la utilidad está aiterando el delicado equilibrio de estos factores $y$, por lo tanto, agravando las tensiones culturales y el sentimiento de incertidumbre".

El capital social y la cultura han comenzado a instalarse en el centro del debate sobre el desarrollo, no como adiciones complementarias a un modelo de alto vigor que se perfecciona un poco más con ellos. Todo el modelo está sufriendo severas dificultades por sus distancias con los hechos, y las críticas procedentes de diversos orígenes se encaminan de un modo u otro a "recuperar la realidad" con 
miras a producir, en definitiva, políticas con mejores chances respecto a las metas finales. En ese encuadre, el ingreso al debate de los mismos forma parte del esfuerzo por darle realidad a toda la reflexión sobre el desarrollo.

El replanteo del modelo no se está haciendo solamente a través de la inclusión de diversas variables ausentes. Está en discusión un aspecto subyacente más profundo, la lógica de las interrelaciones. Una parte signíficativa del nuevo debate está concentrado en el análisis de cómo se han subestimado los encadenamientos recíprocos entre las diversas dimensiones, y cómo ello ha generado errores de consideración en la preparación de políticas. Alessina y Peroti (1994). por ejemplo, subrayan sobre una interrelación clave: "... la desigualdad en los ingresos es un determinando importante de la inestabilidad política. Los países con un ingreso más desigualmente distribuido son políticamente más inestables. A su vez la inestabilidad política tiene efectos adversos sobre el crecimiento".

Las áreas económica, política y social están inextricablemente ligadas. Lo que suceda en cada una de ellas va a condicionar severamente las otras. La visión puramente economicista del desarrollo puede tropezar, en cualquier momento, con bloqueos muy serios que surgen de las otras áreas, $\mathrm{y}$ asi se ha dado en la realidad.

Hay en curso, en ese marco, una reevaluación integral de las relaciones entre crecimiento económico y desarrollo social. En la visión convencional se suponia que, alcanzando tasas significativas de crecimiento económico, el mismo se "derramaría" hacia los sectores más desfavorecidos y los sacaría de la pobreza. El crecimiento seria, al mismo tiempo, desarrollo social. Las experiencias concretas han indicado que las relaciones entre desarrollo económico y desarrollo social son de carácter mucho más complejo. El seguimiento de la experiencia de numerosos paises, efectuado por las Naciones Unidas a través de sus informes de Desarrollo Humano, no encuentra corroboración para los supuestos del llamado modelo de derrame. No basta el crecimiento para solucionar la pobreza. Siendo absolutamente imprescindible, el mismo puede quedar estacionado en ciertos sectores de la sociedad, y no llegar a los estratos sumergidos. Pueden incluso darse tasas significativas de crecimiento y, al mismo tiempo, continuar en vigencia agudas carencias para amplios sectores de la población. James Migdley (1995) señala que esa forma de crecimiento ha caracterizado a muchas naciones desarrolladas y en desarrollo en los últimos años, y la denomina "desarrollo distorsionado". El crecimiento, constata, no ha sido acompañado en ellas por un mejor acceso a protección de salud, educación, servicios públicos y otros factores que contribuyen al bienestar social. Se plantea entonces que, junto a los esfuerzos que es desde ya necesario realizar por el crecimiento, deben practicarse activas políticas de desarrollo social, y debe mejorarse la equidad. Formarán parte de dichas políticas inversiones, mantenidas en el tiempo y considerables, en educación y salud, extensión de los servicios de agua potable, instalaciones sanitarias y energía eléctrica, protección a la familia, y otras. Para 
que el crecimiento signifique bienestar colectivo, debe haber simultáneamente desarrollo social.

El análisis de las interrelaciones entre ambos está yendo, incluso, más lejos. Se resalta que son interdependientes. James Wolfensohn (1996), Presidente del Banco Mundial, ha planteado al respecto: "Sin desarrollo social paralelo no habrá desarrollo económico satisfactorio".

Efectivamente, el desarrollo social fortalece el capital humano, potencia el capital social, y genera estabilidad política, bases esenciales para un crecimiento sano y sostenido. Alain Touraine (1997) sugiere que es necesario pasar a una nueva manera de razonar el tema: "Queda asi planteado el principio central de una nueva política social: en vez de compensar los efectos de la lógica económica, esta debe concebirse como condición indispensable del desarrollo económico". La visión que aparece es la de que no es viable el desarrollo social sin crecimiento económico pero el mismo, a su vez, no tendrá carácter sustentable sino está apoyado en un intenso crecimiento social.

Otro eje analizado son las relaciones entre grado de democracia y desarrollo social. Wickrane y Mulford (1996), entre otros, han examinado las correlaciones estadísticas respectivas. Sus datos indican que cuando aumenta la participación democrática, y se dispersa el poder político entre el conjunto de la población, mejoran los indicadores de desarrollo social. Los gobiernos tienden a responder más cercanamente a las necesidades de la mayoría de la población.

Sumando factores, Wolfensohn (1998) sugiere la imprescindibilidad de ir más allá de los enfoques unilaterales: "Debemos ir más allá de la estabilización financiera. Debemos abordar los problemas del crecimiento con equidad a largo plazo, base de la prosperidad y el progreso humano. Debemos prestar especial atención a los cambios institucionales y estructurales necesarios para la recuperación económica y el desarrollo sostenible. Debemos ocuparnos de los problemas sociales.

Debemos hacer todo eso. Porque si no tenemos la capacidad de hacer frente a las emergencias sociales, si no contamos con planes a más largo plazo para establecer instituciones sólidas, si no logramos una mayor equidad y justicia social, no habrá estabilidad política. $Y$ sin estabilidad política, por muchos recursos que consigamos acumular para programas económicos, no habrá estabilidad financiera".

Como se observa, en la imagen transmitida, la estabilidad financiera no es posible sin estabilidad política. Ella a su vez está muy ligada a los grados de equidad y justicia social. El frente a abordar es muy amplio. Es necesario atacar, al mismo tiempo que los problemas económicos y financieros, los sociales, y avanzar en las transformaciones institucionales.

El capital social y la cultura son componentes claves de estas interacciones. Las personas, las familias, los grupos, son capital social y cultura por esencia. Son portadores de actitudes de cooperación, valores, tradiciones, visiones de la realidad, que son su identidad misma. Si ello es ignorado, salteado, deteriorado, se inutilizarán importantes capacidades aplicables al desarrollo, y se desa- 
tarán poderosas resistencias. $\mathrm{Si}$, por el contrario, se reconoce, explora, valora, $y$ potencia su aporte, puede ser muy relevante y propiciar círculos virtuosos con las otras dimensiones del desarrollo.

La crisis de la reflexión convencional sobre el desarrollo en marcha está abriendo, entre otras, la oportunidad de cruzar activamente capital social, cultura, y desarrollo. Hasta hace poco la corriente principal de trabajo sobre desarrollo prestaba limitada atención a lo que sucedia en dichos campos. A su vez, en ellos, muchas indagaciones se realizaban al margen de posibles conexiones con el proceso de desarrollo. La crisis, que busca ampliar el marco de comprensión para poder superar la estrechez evidenciada por el marco usual, crea un vasto espacio para superar los aislamientos. En la sección siguiente se intenta avanzar en esa dirección, explorando algunos de las múltiples interrelaciones posibles.

\section{Capital social, cultura y desarrollo}

Según análisis del Banco Mundial hay cuatro formas básicas de capital; el natural, constituido por la dotación de recursos naturales con que cuenta un país; el construido, generado por el ser humano que incluye diversas formas de capital: infraestructura, bienes de capital, financiero, comercial, etc.; el capital humano, determinado por los grados de nutrición, salud, y educación de su población, y el capital social, descubrimiento reciente de las ciencias del desarrollo. Algunos estudios adjudican a las dos últimas formas de capital, un porcentaje mayoritario del desarrollo económico de las naciones a fines del siglo $X X$. Indican que alli hay claves decisivas del progreso tecnológico, la competitividad, el crecimiento sostenido, el buen gobierno, y la estabilidad democrática.

¿Qué es en definitiva el capital social? El campo no tiene una definición consensualmente aceptada. De reciente exploración se halla, en realidad, en plena delimitación de su identidad, de aquello que es, y de aquello que no es. Sin embargo, a pesar de las considerables imprecisiones, hay la impresión cada vez más generalizada que, al percibirlo e investigario, las disciplinas del desarrollo están incorporando al conocimiento y la acción, un amplísimo número de variables que juegan roles importantes en el mismo, y que estaban fuera del encuadre convencional.

Robert Putnam (1994), precursor de los análisis del capital social, considera en su difundido estudio sobre las disimilitudes entre Italia del Norte e Italia del Sur que, fundamentalmente, lo conforman: el grado de confianza existente entre los actores sociales de una sociedad, las normas de comportamiento cívico practicadas, y nivel de asociatividad que la caracteriza. Estos elementos son evidenciadores de la riqueza y fortaleza del tejido social interno de una sociedad. La confianza, por ejemplo, actúa como un "ahorrador de conflictos potenciales" limitando el "pleitismo". Las actitudes positivas en materia de comportamiento civico, que van desde cuidar los espacios públicos al pago de los impuestos, contribuyen al bienestar general. La existencia de altos niveles de asociacionismo indica que es una sociedad con capacidades para actuar cooperativamente, armar redes, 
concertaciones, sinergias de todo orden a su interior. Este conjunto de factores tendría, según las observaciones de Putnam, mayor presencia y profundidad en Italia del Norte en relación a la Italia del Sur, y habrían jugado un papel definitorio en la superioridad que la primera había evidenciado en materia de performance económica, calidad de gobierno, estabilidad política y otras áreas.

Para otro de los precursores, James Coleman (1990), el capital social se presenta tanto en el plano individual como en el colectivo. En el primero tiene que ver con el grado de integración social de un individuo, su red de contactos sociales, implica relaciones, expectativas de reciprocidad, comportamientos confiables, mejora la efectividad privada, pero también es un bien colectivo. Por ejemplo, si todos en un vecindario siguen normas tácitas de cuidar por el otro y de no-agresión, los niños podrán caminar a la escuela con seguridad, y el capital social estará produciendo orden público.

Diferentes analistas actuales de esta vieja-nueva forma de capital ponen el énfasis en diversos aspectos. Entre otros, para Kenneth Newton (1997), el capital social puede ser visto como un fenómeno subjetivo, compuesto de valores y actitudes que influencian cómo las personas se relacionan entre sí. Incluye confianza, normas de reciprocidad, actitudes y valores que ayudan a las personas a trascender relaciones conflictivas y competitivas para conformar relaciones de cooperación y ayuda mutua. Stpehan Baas (1997) dice que el capital social tiene que ver con cohesión social, con identificación con las formas de gobierno, con expresiones culturales y comportamien- tos sociales que hacen a la sociedad más cohesiva, y más que una suma de individuos. Considera que los arreglos institucionales horizontales tienen un impacto positivo en la generación de redes de confianza, buen gobierno y equidad social. El capital social juega un rol importante en estimular la solidaridad y en superar las fallas del mercado a través de acciones colectivas y el uso comunitario de recursos. James Joseph (1998) lo percibe como un vasto conjunto de ideas, ideales, instituciones y arreglos sociales, a través de los cuales las personas encuentran su voz y movilizan sus energías particulares para causas publicas. Bullen y Onyx (1998) lo ven como redes sociales basadas en principios de confianza, reciprocidad y normas de acción.

En visión crítica, Levi (1996) destaca la importancia de los hallazgos de Putnam, pero acentúa que es necesario dar más énfasis a las vías por las que el estado puede favorecer la creación de capital social. Considera que el foco de Putnam en asociaciones civiles, lejos del Estado, deriva de su perspectiva romántica de la comunidad y del capital social. Ese romanticismo restringiría la identificación de mecanismos alternativos para la creación y uso del capital social, y limitaría las conceptualizaciones teóricas. Wall, Ferrazi, y Schryer (1998) entienden que la teoría del capital social necesita de mayores refinamientos antes de que pueda ser considerada una generalización medible. Serageldin (1998) resalta que, mientras hay consenso en que el capital social es relevante para el desarrollo, no hay acuerdo entre los investigadores y prácticos acerca de los modos particulares en que aporta al desarrollo, en cómo puede 
ser generado y utilizado, y cómo puede ser operacionalizado y estudiado empírcamente.

Mientras prosigue la discusión epistemológica y metodológica totalmente legítima, dado que los estudios sistemáticos sobre el tema recién se iniciaron hace menos de una década, y el mismo es de una enorme complejidad, el capital social sigue dando muestras de su presencia y acción efectiva. En ello queremos concentramos.

Una amplia línea de investigaciones enfocadas a "registrarlo en acción" está arrojando continuamente nuevas evidencias sobre su peso en el desarrollo.

Entre ellas, Knack y Keefer (1996) midieron econométricamente las correlaciones entre confianza y normas de coope: ación cívica y clecimiento económico, en un amplio grupo de países y encontraron que los primeros presentan un fuerte impacto sobre el segundo. Asimismo, su estudio indica que el capital social integrado por esos dos componentes, es mayor en sociedades menos polarizadas en cuanto a desigualdad, y diferencias étnicas.

Narayan y Pritchet (1997) realizaron un estudio muy sugerente sobre grado de asociatividad y rendimiento económico en hogares rurales de Tanzania. Detectaron que aun en esos contextos de alta pobreza, las familias con mayores niveles de ingresos (medidos por los gastos), eran las que tenían un más alto grado de participación en organizaciones colectivas. El capital social que acumulaban a través de esa participación los beneficiaba individualmente y creaba beneficios colectivos $p c$ : orsas vías. Entre ellas:
- sus prácticas agrícolas eran mejores que las de los hogares que no tenían participación; derivaban de su participación información que llevaba a que utilizaran más agroquímicos, fertilizantes, y semillas mejoradas;

- tenían mejor información sobre el mercado;

- estaban dispuestos a tomar más riesgos porque se sentian más protegidos por formar parte de una red social;

- influlan en el mejoramiento de los servicios públicos; así participaban más en la escuela;

- cooperaban más a nivel del municipio.

Señalan los investigadores en sus conclusiones que: "los canales identificados por los que el capital social incrementaba los ingresos, y la solidez econométrica de la magnitud de los efectos del capital social sugieren que el capital social es capital y no meramente un bien de consumo".

La Porta, López de Silanes, Shleifer, y Vishny (1997), trataron de convalidar las tesis de Putnam en una muestra amplia de paises. Sus análisis estadisticos arrojan significativas correlaciones entre el grado de confianza existente en una sociedad y factores como la eficiencia judicial, la ausencia de corrupción, la calidad de la burocracia, y el cumplimiento con los impuestos. Consideran que "los resultados de Putnam para Italia aparecen confirmados a nivel internacional".

Teachman, Paasch y Carver (1997) trataron de medir cómo el capital social influye en el rendimiento educativo de los niños. Utilizaron tres indicadores: la dinámica de la familia, los lazos con la 
comunidad, y el número de veces que un niño ha cambiado de colegio. Encontraron fuerte correlación con un indicador clave de rendimiento, la probabilidad de deserción. Su hipótesis es que el capital social hace más productivas otras formas de capital, como el capital humano y el capital financiero.

La influencia positiva de un componente central del capital social, la familia, en numerosos aspectos ha sido verificada por diversas investigaciones recientes. Cuanto mayor es la solidez de ese capital social básico, mejores los resultados y al revés. Una amplia investigación sobre 60,000 niños en EE.UU. (Wilson, 1994), indica que los niños que vivían con un solo progenitor, eran dos veces más propensos a ser expulsados o suspendido en la escuela, a sufrir problemas emocionales o de conducta, y a tener dificultades con los compañeros. También eran mucho más proclives a tener una conducta antisocial. Katzman (1997) señala que estudios en el Uruguay muestran que los niños concebidos fuera del matrimonio muestran una tasa de mortalidad infantil mucho mayor que el resto, y los que no conviven con ambos padres biológicos exhiben mayores daños en distintas dimensiones del desarrollo psicomotriz. En una investigación en un medio totalmente diferente, en Suecia, en mucho mejores condiciones económicas, sin embargo, se mantiene el peso diferencial de las familias estables en el rendimiento del niño. Jonsson y Gahler (1997) demuestran que los niños que vienen de familias divorciadas muestran menor rendimiento educativo. Hay una pérdida de recursos en relación a aquellos con los que cuenta el niño en las familias estables.
Sanders y Nee (1996) analizan la familia como capital social en el caso de los inmigrantes en EE.UU. Sus estudios indican que el espacio familiar crea condiciones que hacen factible una estrategia clave de supervivencia, entre los inmigrantes, el autoempleo. La familia minimiza los costos de producción, transacción e información asociados con el mismo. Facilita la aparición de empresas operadas familiarmente. Hagan, MacMillan, y Wheaton (1996) señalan que en las migraciones, incluso hacia el interior de un país, hay pérdidas de capital social, y que ellas son menores en familias con padres involucrados con los niños, y madres protectoras, y mayores, si se trata de padres y madres que no se dedican intensamente a los niños.

Kawachi, Kennedy y Lochner (1997) dan cuenta de datos muy sugerentes sobre la relación entre capital social, equidad, y salud pública. El conocido estudio de Alameda County (EE.UU.), confirmado después en estudios epidemiológicos en diferentes comunidades, detectó que las personas con menos contactos sociales tienen peores probabilidades en términos de esperanza de vida, que aquellos con contactos más extensivos. La cohesión social de una sociedad, que facilita los contactos interpersonales es, afirman los autores, un factor fundamental de salud pública. Miden estadísticamente las correlaciones entre capital social representado por confianza y mortalidad en 39 estados de EEUU. Cuanto menor es el grado de confianza entre los ciudadanos, mayor es la tasa de mortalidad promedio. La misma correlación se obtiene al relacionar la tasa de participación en asociaciones voluntarias, con mortalidad. 
Cuanto más baja es la primera, crece la mortalidad. Los investigadores introducen en el análisis el grado de desigualdad económica. Cuanto más alto, demuestran, menor es la confianza que unos ciudadanos tienen en otros. El modelo estadístico que utilizan les permite afirmar que, por cada punto de aumento en la desigualdad en la distribución de los ingresos, la tasa de mortalidad sube dos o tres puntos con respecto a lo que debiera ser. llustran su análisis con diversas cifras comparadas. EEUU, a pesar de tener un ingreso per capita de los más altos del mundo ( $\$ 24.680$ en 1993), tiene una esperanza de vida $(76,1$ en 1993) menor a la de países con menor ingreso como Holanda (\$17.340, esperanza de vida 77,5$)$, Israel ( $\$ 15.130$, esperanza de vida 76,6$)$, y España (\$13.660, esperanza de vida $77,7)$ Una distribución más igualitaria de los ingresos crea mayor armonía y cohesión social, y mejora la salud pública. Las sociedades con mayor esperanza de vida mundial, como Suecia $(78,3)$ y Japón $(79,6)$ se caracterizan por muy altos niveles de equidad. La desigualdad, concluyen los investigadores, hace disminuir el capital social, y ello afecta fuertemente la salud de la población.

El capital social, al margen de las especulaciones y las búsquedas de precisión metodológicas, desde ya válidas y necesarias, está operando en la realidad a diario y tiene gran peso en el proceso de desarrollo. Puede aparecer a través de las expresiones más variadas. Por ejemplo, como destaca Stiglitz (Octubre, 1998), son estratégicas para el desarrollo económico las capacidades existentes en una sociedad para resolver disputas, impulsar consensos, concertar al Estado y el sector privado. Hirschman (1984), pioneramente, ha planteado al respecto un punto que merece toda la atención. Indica que se trata de la única forma de capital que no disminuye o se agota con su uso, sino que por el contrario, el mismo la hace crecer. Señala: "El amor o el civismo no son recursos limitados o fijos, como pueden ser otros factores de producción, son recursos cuya disponibilidad, lejos de disminuir, aumenta con su empleo".

El capital social puede, asimismo, ser reducido o destruido. Moser (1998) advierte sobre la vulnerabilidad de la población pobre, en ese aspecto, frente a las crisis económicas. En ellas resalta: "mientras que los hogares con suficientes recursos mantienen relaciones reciprocas, aquellos que enfrentan la crisis, se retiran de tales relaciones ante su imposibilidad de cumplir sus obligaciones". Fuentes (1998) analiza cómo en Chiapas, México, las poblaciones campesinas desplazadas, al verse obligadas a migrar, se descapitalizaron severamente en términos de capital social, dado que se destruyeron sus vínculos e inserciones básicas. Puede, asimismo, como lo señalan varios estudios, haber formas de capital social negativo como las organizaciones criminales, pero ellas no invalidan las inmensas potencialidades del capital social positivo.

La cultura cruza todas las dimensiones del capital social de una sociedad. La cultura subyace tras los componentes básicos considerados capital social, como la confianza, el comportamiento civico, el grado de asociacionismo. Como lo caracteriza el informe de la Comisión Mundial de Cultura y Desarrollo de la UNESCO (1996), "la cultura es maneras 
de vivir juntos ... moldea nuestro pensamiento, nuestra imagen, y nuestro comportamiento $\cong$. La cultura engloba valores, percepciones, imágenes, formas de expresión y de comunicación, y muchísimos otros aspectos que definen la identidad de las personas, y de las naciones

Las interrelaciones entre cultura y desarrollo son de todo orden, y asombra la escasa atención que se les ha prestado. Aparecen potenciadas al revalorizarse todos estos elementos silenciosos e invisibles, pero claramente operantes, que involucra la idea de capital social.

Entre otros aspectos, los valores de que es portadora una sociedad van a incidir fuertemente sobre los esfuerzos de desarrollo. Como lo ha señalado Amartya Sen (1997), "los códigos éticos de los empresarios y profesionales son parte de los recursos productivos de la sociedad". Si estos códigos subrayan valores afines al proyecto reclamado por amplios sectores de la población, de desarrollo con equidad, lo favorecerán 0 , de lo contrario, lo obstaculizarán.

Los valores predominantes en un sistema educativo en los medios de difusión masiva, y otros ámbitos influyentes de formación de valores, pueden estimular u obstruir la conformación de capital social que, a su vez, como se ha visto, tiene efectos de primer orden sobre el desarrollo. Como lo subraya Chang (1997): "Los valores ponen las bases de la preocupación del uno por el otro más allá del solo bienestar personal. Juegan un rol crítico en determinar si avanzarán las redes, las normas y la confianza". Valores que tiene sus raíces en la cultura, y son fortalecidos o dificultados por esta como el grado de solidaridad, altruismo, respeto, tolerancia, son esenciales para un desarrollo sostenido.

La cultura incide marcadamente sobre el estilo de vida de los diversos grupos sociales. Un significativo estudio realizado en Holanda (Rupp, 1997) trató de determinar diferencias en estilo de vida entre hogares obreros de un mismo nivel socioeconómico, que se diferenciaban netamente en un aspecto. Algunos de ellos enviaban sus niños a escuelas con un fuerte énfasis en lo cultural, y otros a escuelas inclinadas hacia lo económico. Los comportamientos que surgieron eran muy distintos. Los padres culturalmente orientados utilizaban más tiempo y energía en formas de arte sencillas como cantar, ejecutar instrumentos musicales, y leer un libro cada mes. Su estilo de vida incluía el gusto por formas simples del arte y la búsqueda de una vida saludable, natural, y no complicada. Los padres con orientación hacia lo económico se centraban en logros económicos, bienes materiales, y en aspectos como la apariencia externa. Teniendo similares trabajos y niveles de ingresos, la actitud cultural era la variable básica que estaba impulsando comportamientos muy diversos.

En la lucha contra la pobreza la cultura aparece como un elemento clave. Como agudamente lo destaca la UNESCO, en el informe mencionado (1996): "Para los pobres los valores propios son frecuentemente lo único que pueden afirmar" Los grupos desfavorecidos tienen valores que les dan identidad. Su irrespeto, o marginación, pueden ser totalmente lesivos a su identidad y bloquear las mejores propuestas producti- 
vas. Por el contrario, su potenciación y afirmación pueden desencadenar enormes potenciales de energía creativa.

La cultura es, asimismo, un factor decisivo de cohesión social. En ella, las personas pueden reconocerse mutuamente, cultivarse, crecer en conjunto, $y$ desarrollar la autoestima colectiva. Como señala al respecto Stiglitz (Octubre, 1998), preservar los valores culturales tiene gran importancia para el desarrollo, por cuanto siven como una fuerza cohesiva en una época en que muchas otras se están debilitando.

Capital social y cultura pueden ser palancas formidables de desarrollo si se crean las condiciones adecuadas. Su desconocimiento o destrucción, por el contrario, pueden crear obstáculos enormes en el camino hacia el desarrollo. Sin embargo, podría preguntarse: ¿lograr esa potenciación no pertenecerá al reino de las grandes utopias, de un porvenir todavía ajeno a las posibilidades actuales de las sociedades? En la sección siguiente del trabajo se intenta demostrar que ello no es asi, que hay experiencias concretas que han logrado movilizarlos en escala considerable al servicio del desarrollo, y que debe prestárseles la máxima atención para extraer enseñanzas al respecto.

\section{El capital social en acción. Experiencias latinoamericanas}

¿Qué sucede cuando se realiza un trabajo sostenido de largo plazo de movilización de aspectos claves del capital social de una comunidad? ¿Cuáles son las respuestas observables? ¿Qué oportunidades nuevas y qué dificultades aparecen? Es posible obtener indicios signifi- cativos, al respecto, revisando experiencias actualmente en curso. Existe una ampiísima gama de ellas a nivel internacional. Algunas han obtenido celebridad mundial, como la del Grameen Bank de Bangla Desh, dedicado a apoyar financieramente a campesinos pobres, que ha logrado sorprendentes resultados apoyándose en elementos que tienen que ver con grado de asociatividad, confianza mutua, y otras dimensiones del capital social. Nos concentraremos en nuestro trabajo en experiencias de América Latina, que son indicativas del potencial latente en la región en esta materia, y pueden arrojar enseñanzas útiles para formular políticas de desarrollo social en elias. Hemos escogido tres casos que han obtenido resultados de alta relevancia, que son reconocidos en sus paises, y a nivel internacional, como "prácticas sociales de gran éxito" y que son continuamente analizados y visitados para buscar posibilidades de replicarlos, total, o parcialmente.

\subsection{Villa El Salvador, Perú: de los arenales a una experiencia social de avanzada}

En 1971 varios centenares de personas pobres realizaron una invasión de tierras públicas en las afueras de Lima. Se les sumaron miles de habitantes de tugurios de Lima. El Gobierno intervino para expulsarlos, y finalmente accedió a que se radicaran en un vasto arenal ubicado a $19 \mathrm{Km}$ de Lima. Esos 50.000 pobres, que carecian de recursos de toda índole, fundan alli Villa El Salvador (VES). Se les van agregando muchas más personas y su población actual se 
estima en cercana a 300.000 habitantes. La experiencia que desarrollan es considerada muy particular en múltiples aspectos. El plano urbanístico trazado diferencia VES netamente de otras barriadas de pobres. El diseño es el de 1300 manzanas, que configuran 110 grupos residenciales. En lugar de haber un solo centro, en donde funcionen los edificios públicos básicos, el esquema es totalmente descentralizado. Cada grupo residencial tiene su propio centro, en donde se instalaron locales comunales, y espacios para el deporte, actividades culturales, y el encuentro social. Ello favorece la interacción y maximiza las posibilidades de cooperación. Se da un modelo organizativo basado en la participación activa. Partiendo de delegados por manzana, y por grupos residenciales, crean una organización, CUAVES, que representa a toda la comunidad y que va a tener un peso decisivo en su desarrollo. Establecen casi 4000 unidades organizativas para buscar soluciones y gestionar los asuntos comunitarios. En ellas participa la gran mayoria de la población, llegándose a que cerca del $50 \%$ de los mayores de 18 años ocupan algún cargo dirigencial en términos organizacionales.

Desarrollan en estos arenales, carentes de todo orden de recursos, y casi incomunicados (debían recorrer $3 \mathrm{Km}$ para encontrar una vía de acceso a Lima), un gigantesco esfuerzo de construcción basado, centralmente, en el trabajo voluntario de la misma comunidad. Un inventario de situación de fines de 1989 dice que, en menos de dos décadas, tenian 50.000 viviendas, 38.000 de ellas construidas por los pobladores, un $68 \%$ con materiales nobles (ladrillo, ce- mento, techos de concreto, etc.), habían levantado con su esfuerzo 2.800 .000 metros cuadrados de calles de tierra afirmada y construido, en su mayor parte, con los recursos y el trabajo de la comunidad, 60 locales comunales, 64 centros educativos, y 32 bibliotecas populares. A ello se sumaban 41 núcleos de servicios integrados de salud, educación y recuperación nutricional, centros de salud comunitarios, una red de farmacias, y una razonable estructura vial interna con 4 rutas principales y 7 avenidas perpendiculares, que permitían la comunicación interna. Plantaron medio millón de árboles.

Permaneciendo pobres y con serios problemas ocupacionales, como toda Lima, los logros sociales obtenidos por VES eran muy significativos. La tasa de analfabetismo habia descendido de $5,8 \%$ a $3,5 \%$. La tasa de matrícula en primaria había alcanzado el $98 \%$ y, en secundaria, era superior al $90 \%$, todas cifras superiores a las medias nacionales, $y$ mucho mejores que las de las poblaciones pobres similares. En salud, las campañas de vacunación realizadas con apoyo en la comunidad, que habían cubierto a toda la población, la organización de la comunidad para la salud preventiva, y el control de embarazos, habian incidido en un fuerte descenso de la mortalidad infantil, a 67 por mil, cifra muy inferior a la media nacional que estaba en 88 a 95 por mil. La tasa de mortalidad general era también inferior a los promedios nacionales. Se registraban, asimismo, avances en materia de obtención de servicios de agua, desagüe y electricidad, en un plazo que se estimó menor, en 8 años, al que tardaban otros barrios pobres para lograrios, y se había desarrollado una con- 
siderable infraestructura, equipamiento $y$ servicios comunitarios superior a la de otras barriadas.

El enorme esfuerzo colectivo realizado ha sido descripto por el varias veces Alcalde de VES, Michel Azcueta (citado por Zapata, 1996), del siguiente modo: "El pueblo de Villa El Salvador, con su esfuerzo y su lucha, ha ido construyendo una ciudad de la nada, con cientos de kilómetros de redes de agua y de luz, pistas, colegios, mercados, zona agropecuaria, y hasta un parque industrial, conseguido también con lucha por los pequeños industriales de la zona".

Se plantea una pregunta de fondo: ¿cómo fue posible lograr estos resultados partiendo de la miseria, en un marco natural tan difícil, en medio de la aguda crisis económica que vivió el Perú, como toda la región, en los ochenta, y de todo orden de dificultades? Las claves para entender los logros, que no erradicaron la pobreza, pero mejoraron aspectos fundamentales de la vida de las gentes de VES, y la convirtieron en una barriada pobre diferente, parecen hallarse en elementos incluidos en la idea del capital social.

La población originaria de VES estaba conformada, en su mayor parte, por familias llegadas de la sierra peruana. Los campesinos de los Andes carecian de toda riqueza material, pero tenían un rico capital social. Llevaban consigo la cultura y la tradición indígena, y una milenaria experiencia histórica de cooperación, trabajo comunal y solidaridad. Aspectos centrales de esa cultura, como la práctica de una intensa vida comunitaria, donde convive la propiedad comunal de servicios útiles para todos, al mismo tiempo que la propiedad familiar e individual, fueron aplicados en VES. Esa cultura facilitó el montaje de esa extendida organización participativa, donde todos los pobladores fueron convocados a ser actores de las soluciones de los problemas colectivos. Funcionó con fluidez, a partir de las bases históricas favorables, que habia en la cultura campesina peruana. Hasta recetas técnicas, como las lagunas de oxidación utilizadas por los Incas, fueron empleadas intensamente en VES. Ellas permiten un procesamiento de los desechos generados, por vía de un sistema de lagunas que lleva a la producción de abonos, que después se usaron en generar zonas verdes y producción agrícola.

La visión anclada en la cultura de los pobladores de VES, de la trascendencia del trabajo colectivo como medio para buscar soluciones, impregnó desde el inicio la historia de la Villa. Aparece reflejada vívidamente en cómo se enfrentó el problema de construir escuelas. Michel Azcueta (citado por Zapata, 1996) narra: "... desde la instalación misma, la población se organizó para que se construyeran escuelas y los niños no perdieran el año escolar. Se formaron doce comités proescuela en los primeros tres meses y se inició la construcción de muchas aulas en un esfuerzo que, mirado a la distancia, parece enorme y que no se entiende sin acudir a una explicación sobre sus motivaciones subjetivas. Se empezó a dictar clases en aulas que usaban esteras como paredes, las que se impermeabilizaban con plásticos para mínimamente combatir el frío invernal, mientras que el suelo era de tierra apenas afirmada, y los escasos ladrillos fueron reservados para 
Capital social y cultura en el proceso de desarrollo Kliksberg, Bernardo

ser usados como precarios bancos por los niños. Estas aulas fueron construidas en jornadas colectivas dominicales, con un entusiasmo y febrilidad que han dejado un recuerdo imborrable entre sus protagonistas".

A favor de estas condiciones se creó en VES un amplio y sólido tejido asoclativo. Se constituyeron organizaciones de jóvenes, de mujeres, de madres, cooperativas de mercados, asociaciones de pequeños industriales y comerciantes, rondas urbanas, coordinadoras y brigadas juveniles, ligas deportivas, grupos culturales de todo orden, etc. La asociatividad cubrió en VES los más variados aspectos. Entre ellos: productores uniéndose para comprar insumos en conjunto, buscar mancomunadamente maquinarias, mejorar la calidad; más de un centenar de clubes de madres, que crearon y gestionaron ejemplarmente 264 comedores populares y 150 programas de vaso de leche; jóvenes que dirigen y llevan adelante centenares de grupos culturales, artísticos, bibliotecas populares, clubes deportivos, asociaciones estudiantiles, talleres de comunicación, etc.

El trabajo de la propia comunidad, organizada en marcos cabalmente participativos, estuvo en la base de los avances que fue logrando en corto tiempo. El proceso "disparó" el capital social latente, que se fue multiplicando. La creación, a partir de la nada, de un municipio entero por su población, generó una identidad sólida e impulsó la autoestima personal y colectiva. Como señala Carlos Franco (1992), la ciudad que se creó era la expresión de sus habitantes. No eran simplemente sus pobladores, sino sus constructores. Al crear VES, y desarrollarla, se crearon a sí mismos. Por eso como marca, cuando se pregunta a los habitantes de VES de dónde son, no contestan como otros, llegados del ínterior, haciendo referencia a su lugar de nacimiento, sino que dicen "soy de Villa", el lugar que les dio una identidad que valoran altamente. El proceso de enfrentar desafíos muy difíciles y avanzar, fue asimismo fortaleciendo su autoestima, estímulo fundamental para la acción productiva. Describe Franco: "... cuando se asiste con alguna frecuencia a reuniones de pobladores y se conversa con los 'fundadores' de la comunidad, o sus dirigentes, no resulta difícil advertir expresiones recurrentes de autoconfianza colectiva, certidumbres sobre su disposición de un poder organizado, una cierta creencia en las capacidades de la comunidad para proponerse objetivos y unirse para su logro".

La autoestima fue especialmente cultivada también en las escuelas de VES. Los maestros trataron de liberar a los niños de todo sentimiento de inferioridad derivado de sus condiciones de hijos de familias pobres. Procuraron darle seguridad a los niños, que no se sintieran en minusvalía.

La cultura cumplió un papel significativo en la experiencia desde sus inicios. En 1974 Azcueta creó, y llevó adelante, el Centro de Comunicación Popular, espacio destinado a actividades culturales extracurriculares de toda índole. Alli surgieron primero Talleres de Teatro y Música, y luego de otras áreas, y se desplegó una intensísima labor. Desde esos espacios culturales se procuraba estimular la participación de la población en las asambleas de toma de decisiones y las actividades comunales. El teatro de VES pro- 
dujo, a lo largo de los años, piezas que lo llevaron a los escenarios metropolitanos y nacionales. La actividad cultural formó parte de la vida cotidiana de la población. Describe Franco: "... el intermitente funcionamiento de 39 altoparlantes, las competencias deportivas internas, los programas radiales de la comunidad, los talleres de comunicación, los numerosos grupos artísticos y culturales, la nueva y moderna radio del Centro de Comunicación Popular, y el creciente número de peñas y grupos musicales, contribuyen al desarrollo de una intensa y bullente vida comunal".

El esfuerzo de construcción comunitaria de VES, realizado en las más difíciles condiciones, fue presidido y orientado por ciertos valores. La población definió su proyecto como la conformación de una comunidad autogestionaria participativa. Una visión colectiva centrada en la promoción de valores comunitaristas, de la participación activa y de la autogestión, enmarcó todo el esfuerzo. En 1986 VES se convirtió en un Municipio. Al estructurarlo se mantuvieron todos los principios anteriores. Así se estableció que las decisiones comunales serían la base de las decisiones municipales. Recientemente VES estableció, con asistencia de varias $\mathrm{ONG}$, el Diario El Comercio, y otras entidades, un sistema destinado a facilitar la participación de la población empleando la informática. Entre sus elementos: el Consejo Municipal transmite sus sesiones en circuito cerrado a la Villa; en la misma hay terminales de computadora, y los habitantes pueden recibir, a través de ellos, información sobre qué se va a tratar en dichas sesiones, y elementos de juicio al respecto, y hacen llegar al
Colisejo sus puntos de vista; el Consejo realiza, a través del sistema de computación, referéndums continuos sobre las opiniones de los habitantes.

La experiencia de VES ha sido reconocida mundialmente siendo objeto de continuas distinciones. En 1973 la UNESCO la premió como una de las más desafiantes experiencias en educación popular, en 1986 el Diario La República (de Lima) la declaró "personaje del año del pais", en 1987 las Naciones Unidas designó a VES Ciudad Mensajera de la $\mathrm{Paz}$, distinguiéndola como promotora ejemplar de formas de vida comunitaria. También en 1987 se le otorgó el Premio Príncipe de Asturias, del Rey de España, por el impresionante desarrollo alcanzado por la comunidad en el área social y cultural. Asimismo, entre otras, recibió el Premio Nacional de Arquitectura y Desarrollo Urbano del Perú, y un premio por ser la comunidad con un mayor grado de forestación y arborización. En 1985 el Papa Juan Pablo Il visitó Villa El Salvador destacando sus logros y señalando: "Con gran alegría me he enterado de la generosidad con que muchos de los habitantes de este 'pueblo joven' ayudan a los hermanos más pobres de la comunidad, en los comedores populares y familiares, en los grupos para atender a los enfermos, en las campañas de solidaridad para soconer a los hermanos golpeados por las catástrofes naturales".

En VES no se lograron solucionar los problemas de fondo causantes de la pobreza, que tienen que ver con factores que exceden totalmente a la experiencia y forman parte de problemas generales del país. Sin embargo, se obtuvieron avances considerables respecto a otras 
poblaciones pobres, y se creó un perfil de sociedad muy particular, que mereció la larga lista de premios obtenida. La potenciación del capital social jugó un papel decisivo en los logros de VES. Factores no visibles, silenciosos, que actúan en las entrañas del tejido social, desempeñaron aquí un rol positivo constante. Entre ellos: el fomento permanente de formas de cooperación, la confianza mutua entre los actores organizacionales, la existencia de un comportamiento cívico comunal, constructivo y creador, la presencia de valores comunes orientadores, la movilización de la cultura propia, la afirmación de la identidad personal, familiar y colectiva, el crecimiento de la autoestima en la misma experiencia. Todos estos elementos fueron dinamizados por el modelo genuinamente participativo adoptado por la comunidad. Con desde ya avances, y retrocesos, pasando por momentos muy duros como los que se dieron durante el auge de la violencia en el país, VES se halla en 1999, como se mencionó, buscando formas todavía más activas de participación de la comunidad, y como lo indican periódicos del Perú se ha convertido, probablemente, en el primer Municipio de América Latina que ha sumado, a las metodologías de participación democrática usuales, la democracia virtual.

\subsection{Las ferias de consumo familiar de Venezuela: los dividendos del capital social}

La pregunta de cómo abaratar el costo de los productos alimenticios, para los sectores humildes de la población, ha tenido una respuesta significativa en la ciudad de Barquisimeto, Venezuela. Ini- ciadas en 1983, las ferias de consumo familiar han logrado reducir en un $40 \%$ los precios de venta al público de productos verdes como frutas y hortalizas, $y$ en un 15 al $20 \%$ los precios de víveres. Ello beneficia semanaimente a 40.000 familias de esa ciudad de un millón de habitantes. Esas familias, integrantes principalmente de estratos bajos y medios bajos, obtienen comprando en las Ferias un ahorro anual que se estima en 10,5 millones de dólares.

Las ferias están integradas por un amplio número de organizaciones de la sociedad civil. Formaimente constituyen parte de la Central Cooperativa del Estado Lara (CECOSESOLA), pero en su operación intervienen grupos de productores, asociaciones de consumidores y pequeñas empresas autogestionarias. Asi, en ellas participan 18 asociaciones de productores agrícolas, que agrupan a cerca de 600 productores, y 12 unidades de producción comunitaria. Esos pequeños y medianos agricultores y los productores de víveres colocan su producción a través de las Ferias. Las Ferias comprenden 50 puntos de ventas, que operan los tres últimos días de la semana, $y$ venden directamente a la población 300 toneladas semanales de productos hortofruticolas y víveres comunes para el consumo hogareño.

Las ferias venden, como producto básico, un kilo de productos hortofrutícolas por un precio único. Ello simplifica al máximo su operación. Entre los productos se hallan: papa, tomate, zanahoria, cebolla, pimentón, lechuga, ñame, ocumo, apio, ayuma, yuca, repollo y plátano. Los hacen llegar a través de sus transportes y locales directamente del pequeño 
productor al consumidor. Todos salen ganando. El pequeño productor, antes dependiente de "roscas" de la comercialización y de vaivenes continuos, tiene a través de ellas asegurada la venta de su producción a precios razonables, y es uno de los cogestores de toda la iniciativa. Los consumidores reciben productos frescos a precios mucho más reducidos que los del mercado.

Las ferias han crecido rápidamente durante estos 15 años, y se han convertido en el principal proveedor de alimentos y productos básicos de la ciudad de Barquisimeto.

Su expansión puede observarse en el siguiente cuadro:

Como se observa, partiendo de una sola feria, y casi sin capital inicial, las
Ferias han crecido aceleradamente en todos los indicadores incluidos en el cuadro. Entre 1990 y 1997 aumentó en un $78 \%$ el número de toneladas semanales de productos verdes vendidos, y se duplicó la cantidad de familias atendidas.

¿Cuáles han sido las bases de estos éxitos económicos y de eficiencia de un conjunto de organizaciones de base de la sociedad civil, sin capital, que se lanzaron a un mercado como el de comercialización de productos agroalimentarios de alta competitividad y escasos márgenes de beneficio?

En la base del éxito parecen hallarse elementos claves del capital social. Los actores de la experiencia señalan, como base de sus logros (Ferias de Consumo Familiar, 1996):

Evolución de las ferias de consumo familiar

\begin{tabular}{|c|c|c|c|}
\hline Año & 1984 & 1990 & 1997 \\
\hline Unidades de venta & 1 & $87^{\star}$ & $105^{\star *}$ \\
\hline $\begin{array}{l}\text { Venta semanal de productos hortofruticolas } \\
\text { (en toneladas) }\end{array}$ & 3 & 168 & 300 \\
\hline Número de familias atendidas & 300 & 20.000 & 40.000 \\
\hline Número de trabajadores & 15 & 400 & 700 \\
\hline Número de productores agrícolas & 15 & 100 & 500 \\
\hline Número de organizaciones de productores & 1 & $\mathrm{n} / \mathrm{d}$ & 18 \\
\hline Número de unidades de producción comunitaria & 1 & 9 & 12 \\
\hline
\end{tabular}

* Incluye todo el Estado Lara; aproximadamente la mitad en Barquisimeto

* Incluye 50 ferias y 55 centros de abastecimiento solidario

Fuentes: CECOSESOLA. Ferias de Consumo Familiar. Estado Lara. Barquisimeto, 1990.

CECOSESOLA. Presentación del programa de Ferias de Consumo Familiar

en reunión del Grupo Santa Lucía. Puerto La Cruz, Venezuela. Octubre de 1997.

Tomado de Gómez Calcaño, Luis (1998). 
"Tratando de buscar las claves para comprender los logros que hemos obtenido, podemos mencionar:

1. Una historia de formación de un capital social y humano

2. Potenciar el capital social por encima del financiero

3. Unas formas novedosas de gestión participativa"

Los varios centenares de trabajadores que llevan adelante las ferias y las asociaciones vinculadas a ellas, han establecido un sistema organizacional basado en la cooperación, la participación, la horizontalidad, y fuertemente orientado por valores.

Las Ferias tienen tras suyo una concepción de vida que privilegia, según indican sus actores, la solidaridad, la responsabilidad personal y de grupo, la transparencia en las relaciones, la creación de confianza, la iniciativa personal, el amor al trabajo.

Esta tabla de valores no permanece confinada a alguna declaración escrita, como sucede con frecuencia, sino que se trata de cultivar sistemáticamente en la organización. Un observador externo (Bruni Celli, 1996) describe así la dinámica cotidiana de las ferias: "Los valores cooperativistas de crecimiento personal, apoyo mutuo, solidaridad, frugalidad, $y$ austeridad; de enseñar a otros, de no ser egoista y dar lo mejor de si para la comunidad, son temas de reflexión continua en las ocho o más horas de reuniones a las que asisten todos los trabajadores de CECOSESOLA a la semana. El alto número de horas dedicadas a reuniones podrían verse como una pérdida en productivi- dad, pero son el principal medio a través del cual se logra la dedicación, el entusiasmo y el compromiso de los trabajadores de la organización".

Enmarcado en esos valores, el diseño organizacional adoptado parece haber jugado un rol decisivo en los resultados obtenidos. Está centrado en principios como la participación activa de todos los integrantes de la organización, en la comunicación fluida, el análisis y el aprendizaje conjunto, y la rotación continua de tareas. Uno de sus rasgos es que todos los centenares de trabajadores de la organización ganan igual remuneración, que es un $57 \%$ superior al salario minimo nacional. Además, la organiza. ción ha creado un fondo de financiamiento que presta a tasas bajas, y un fondo integrado de salud. Siendo una remuneración modesta, los miembros de la organización han indicado que tienen otros incentivos, como participar de un proyecto con estos valores, formar parte de un ambiente de trabajo democrático y no autoritario, tener posibilidades de formación y desarrollo.

Los mecanismos concretos de operación de la organización incluyen: reuniones semanales de cada grupo para evaluar y planificar; toma de decisiones por consenso; información compartida; disciplina y vigilancia colectiva; trabajo descentralizado de cada grupo, y la mencionada rotación de responsabilidades.

A ello se suman los espacios de encuentro denominados "convivencias". Están dedicados al encuentro personal y social.

Estos rasgos organizacionales coinciden con muchas de las recomendaciones de la gerencia de avanzada. Son 
propicios para crear lo que se llama hoy "una organización que aprende", y "una organización inteligente". El modelo organizacional de las Ferias tiene gran flexibilidad, les permite absorber por todos sus "poros" información sobre lo que sucede en la realidad $y$, al compartirla internamente, aumenta la capacidad de reacción ante los cambios en la misma. Asimismo, permite monitorear sobre la marcha los procesos, detectando rápidamente los errores y corrigiéndolos. El clima de confianza creado entre sus integrantes evita los cuantiosos costos de la desconfianza y el enfrentamiento permanente, muy característicos de otras organizaciones. Por otra parte, los elementos del modelo favorecen un sentimiento profundo de pertenencia que es un estímulo fundamental para la productividad y la búsqueda continua de cómo mejorar la tarea.

Las Ferias han resistido todos los pronósticos sobre que difícilmente podrían enfrentar los rigores del mercado. Por el contrario, se han posicionado en una situación de liderazgo en el mercado respectivo, obligando a otros competidores empresariales a tratar de ajustar sus precios para poder tener un espacio. Se han convertido en el principal comercializador de alimentos básicos de la cuarta ciudad en población, de Venezuela y, a pesar de su dimensión local por las cifras que manejan, son una de las principales empresas de mercadeo de alimentos del país entero. Se han demostrado como una empresa con plena sustentabilidad que, en 15 años, ha ido ampliando continuamente su operación. Actualmente su modelo está inspirando réplicas en diver$s$ is ciudades de Venezuela. Las claves de ia excelencia alcanzada no están, en este caso, en grandes inversiones de capital manejadas con criterios empresariales clásicos de maximización de la rentabilidad, y con una gerencia vertical "dura". El capital que han movilizado es, esencialmente, "capital social". Han promovido ciertos valores latentes en la sociedad civil, han mostrado la posibilidad de un proyecto colectivo, al mismo tiempo eficiente productivamente, útil socialmente, $y$ atractivo como marco de vida, y han potenciado, a través de su particular estilo gerencial, que ellas han denominado "gestión solidaria", elementos básicos de la concepción aceptada de capital social, como la asociatividad, la confianza mutua, y normas de comportamiento positivas hacia lo comunitario.

Su objetivo, en realidad, no se reduce a lo económico. Lo declara así uno de los líderes de la experiencia, Gustavo Salas (1991): "... el objetivo fundamental del programa, y su mayor aporte a la organización popular, está dado por el proceso formativo que se intenta propiciar desde todas sus actividades concretas".

Cuando son observadas desde el exterior, pareciera que se está frente a un mecanismo audaz e innovativo de mercadeo. Pero como señala un agudo observador, Luis Delgado (1998): "... en realidad, son una escuela de vida. Una escuela que potencia el desarrollo humano en colectivo, e impulsa la felicidad en las relaciones en el trabajo, en la vida familiary personal".

Analistas locales como Machado y Freytes (1994) señalan que, a su vez, se han apoyado en el vasto capital social existente en el Estado Lara. Existe en el mismo una vieja tradición cooperativa, es el estado de Venezuela con mayor pre- 
sencia de organizaciones cooperativas. Tenía en 1994, 85 cooperativas, de ellas, 36 de servicios múltiples. Asimismo, presenta una densa red de organizaciones no gubernamentales (más de 3500 ), numerosas asociaciones de vecinos y otras formas de organización social. Hay en el Estado Lara todo un habitat "cultural" que favorece el desarrollo del capital social y que dio pie a una experiencia de estas caracteristicas.

\subsection{El presupuesto municipal participativo de Porto Alegre; ampliando el capital social existente}

La experiencia de Presupuesto Municipal Participativo iniciada en la Ciudad de Porto Alegre, del Brasil, en 1989, se ha transformado en una experiencia "estrella" a nivel internacional, concitando amplísima atención. Entre otras expresiones de ese reconocimiento en 1996, las Naciones Unidas la escogió como uno de los 40 cambios urbanos elegidos, en todo el mundo, para ser analizados en la Conferencia Mundial sobre Asentamientos Humanos (Habitat II, de Estambul) y, en 1997, el Instituto de Desarrollo Económico del Banco Mundial, realizó una Conferencia Internacional en Porto Alegre, con la presencia de representantes de 9 países de la región para

examinar la experiencia. Asimismo, el BID la seleccionó como una de las experiencias incluidas en su Libro Maestro sobre Participación. A nivel nacional, cerca de 70 Municipios del Brasil están iniciando experiencias similares inspiradas en Porto Alegre.

Este impacto se debe a resultados muy concretos. La Ciudad de Porto Ale- gre, de 1.300 .000 habitantes, tenía en 1989 importantes problemas sociales, $y$ amplios sectores de su población tenian limitado acceso a servicios básicos. El cuadro era, asimismo, de penuria aguda de recursos fiscales. El nuevo Alcalde electo (elegido en 1999 Gobernador del Estado al que pertenece la ciudad Río Grande do Sul), resolvió invitar a la población a cogestionar el proceso presupuestario de modo de administrar, de acuerdo a sus reales prioridades, los recursos limitados, y aumentar su eficiencia. La cogestión ofrecida se realizaría sobre el rubro de inversiones de dicho presupuesto. En este caso la invitación no fue mero "discurso", sino que se estableció un complejo y elaborado sistema que posibilitaba la participación masiva. La ciudad fue dividida en 16 regiones, en cada una de las cuales se analizan las cifras de ejecución presupuestaria, las estimaciones futuras, y se identifican, a nivel barrial, prioridades que luego se van concertando y compatibilizando a nivel regional $y$ global. Junto a las regiones, existe otro mecanismo de análisis y decisión que funciona por grandes temas de preocupación urbana: desarrollo urbano, transporte, atención de la salud, tiempo libre, educación y cultura. Rodadas, reuniones intermedias, plenarios, y otras formas de reunión se van sucediendo durante todo el año, con participación de públicos amplios, en algunos casos, delegados elegidos por los mismos, en otros, y la colaboración de los funcionarios del municipio. El presupuesto que se va conformando de abajo hacia arriba, es finalmente sancionado formalmente por el Consejo Municipal. 
La población reaccionó con una "fiebre participativa", como la liama Navarro (1998), a la convocatoria del Alcalde. En 1995 se estimaba que 100.000 personas participaban en el proceso.

Los resultados han sido sorprendentes y han echado por tierra los vaticinios pesimistas augurados por algunos sectores, que veían como una heterodoxia inadmisible la entrega de una cuestión tan técnica y delicada como el presupuesto, a un proceso de participación popular Por un lado la población determinó sus reales necesidades. Ello generó una precisa identificación de prioridades, reorientando recursos hacia los problemas más sentidos. Por otra parte, todo el trayecto del presupuesto, otrora impenetrable y cerrado, se abrió totalmente para la ciudadanía. Al compartirse con ella, toda la información se convirtió en transparente. Ello generó condiciones propicias a la erradicación de toda forma de corrupción. La población, masivamente, hizo el control social de la ejecución y confección de la partida de inversiones, que significó el $15 \%$ del presupuesto total y sumó, en el período 1989/95, 700 millones de dólares. Asimismo, al existir reglas de juego claras sobre cómo sería el proceso de toma de decisiones, se recortaron al máximo los espacios para prácticas clientelares arbitrarias.

La correspondencia del presupuesto, con las necesidades prioritarias y la mejora de su administración, llevaron a resultados muy significativos. Entre ellos, de 1990 a 1996, el abastecimiento de agua potable subió de 400.000 hogares atendidos, a 484.000, cubriéndose el $98 \%$ de la población. En materia del alcantarillado, mientras que en 1989 sólo el
$48 \%$ de los hogares estaban conectados a la red de cloacas, en 1997 era el $80,4 \%$, cuando el promedio del Brasil es el $49 \%$. El programa de legitimación de la propiedad de la tierra a sectores pobres, y asentamientos humanos, benefició entre 1990 y 1996, a 167.408 personas, el $13 \%$ de toda la población. La pavimentación de calles alcanzó a $30 \mathrm{~km}$ por año, en las áreas pobres de la ciudad. La matrícula en escuela primaria y secundaria subió en un $159 \%$ entre 1989 y 1997 , y el Municipio creó un programa de alfabetización de adultos que tenia, en 1997, 5.277 participantes.

La identificación de prioridades ajustadas a las reales, y todo el sistema, habian producido una vasta reasignación de recursos que, sumada a la participación colectiva en el monitoreo de los pro. cesos de ejecución, posibilitaron resultados de esta magnitud.

La población se transformó en un gran actor del presupuesto municipal. Como describe el Libro Maestro sobre Participación del BID (1997):

"Los ciudadanos de Porto Alegre han tenido oportunidad de pasar por un proceso plenamente participativo por haber:

- expresado su comprensión de los problemas cruciales que enfrenta la ciudad;

- establecido prioridades de los problemas que merecen más inmediata atención;

- seleccionado las prioridades y generado soluciones prácticas;

- tenido oportunidad de comparar con las soluciones creadas en otras regiones de la ciudad y en otros grupos de temas; 
- decidido, con el apoyo de técnicos de la oficina del Alcalde, en invertir en los programas menos costosos y más factibles de atender;

- tomado la decisión definitiva sobre la aprobación, o nó, del plan de inversiones; $y$

- revisado los éxitos y fracasos del programa de inversiones para mejorar sus criterios para el año siguiente".

La amplia base social de apoyo a cambios presupuestarios profundos, se expresó también en una fuerte presión hacia hacer más progresivo y eficiente el sistema fiscal del Municipio, y se realizaron importantes reformas en el mismo que permitieron ampliar la recaudación y mejorar la equidad fiscal.

En su conjunto, cambió sensiblemente la fisonomía política tradicional del Municipio, semejante a la de muchos otros de la región. Entre otras expresiones de este cambio, se hallaron: una nueva redistribución de funciones entre Municipio y sociedad civil, activación enérgica de la misma, instalación de formas de democracia directa junto a la representativa, reducción muy fuerte del margen para la corrupción, al hacerse tan trasparente y vigilado el proceso de manejo de las finanzas publicas, condiciones desfavorables para las prácticas clientelares, descentralización de las decisiones.

El proceso se basó en el capital social existente en esa sociedad. Habia en ella una tradición relevante de asociaciones de la comunidad. Se movilizaron activamente, en el mismo, y tienen un papel fundamental en los diversos niveles de deliberación creados. Como señala $\mathrm{Na}$ varro, el proceso tuvo un eje decisivo en la voluntad política del Alcalde de superar los esquemas de concentración del poder, usuales, y convocar a la población y a dichas asociaciones $a$, en definitiva, "compartir el poder". Ese llamado y la instalación de mecanismos genuinos de participación actuaron como ampliadores del capital social. Se disparó la capacidad de cooperación, se creó un clima de confianza entre los actores, se generaron estímulos significativos para un comportamiento cívico constructivo. La cultura asociativa preexistente fue un cimiento esencial para que la población participara, y a su vez, fue fortalecida enormemente por el proceso. El proceso demostró las potencialidades que aparecen cuando se superan las falsas oposiciones entre Estado y sociedad civil, y se produce una alianza entre ambos.

En Porto Alegre, el capital social se comportó de acuerdo a las previsiones de Hirschman (1984), antes señaladas. Al invertirse mediante el presupuesto participativo, en mecanismos que implican su uso intensivo, creció. Los señala con precisión el libro del BID antes mencionado (1997), destacando que el proceso participativo: "... ha tenido un enorme impacto en la habilidad de los ciudadanos para responder a los retos organizadamente, como comunidad, y en la capacidad de trabajar en forma conjunta para mejorar la calidad de la administración pública y, en consecuencia, la calidad de la vida".

\subsection{Algunas enseñanzas}

Las tres experiencias reseñadas, sumariamente, han obtenido importantes impactos, demostrado fuerte sustentabilidad, y alcanzado múltiples reconocimien- 
tos. ¿Cuáles han sido las claves de su éxito? Las experiencias se han desarrollado en medios muy diferentes, $y$ han atacado aspectos muy diversos, sin embargo, es posible encontrar como respuesta a esta pregunta, algunos elementos comunes a todas ellas, que han influido significativamente en los resultados.

En primer lugar, en los tres casos, las estrategias utilizadas se han basado en la movilización de formas de capital no tradicional. Se ha apelado a elementos intangibles, no captados por los abordajes productivos usuales. Se ha promovido la puesta en acción de fuerzas latentes en los grupos sociales, que pueden incidir considerablemente en su capacidad de generar soluciones, y de crear. En todas las experiencias se hizo entrar en juego la capacidad de buscar respuestas y ejecutarlas cooperativamente, se creó un clima de confianza entre los actores, se partió de sus culturas, se las respetó cabalmente, y se estimuló su desarrollo, y se fomentó un estilo de conducta cívica solidario y atento al bienestar general. El estímulo a estos factores, y otros semejantes, creó energías comunitarias y organizacionales que pudieron llevar adelante amplios procesos de construcción, partiendo de la miseria en Villa El Salvador, de recursos infimos en las Ferias de Barquisimeto, y de recursos limitados y déficits en Porto Alegre.

Un segundo rasgo común es la adopción de un diseño organizacional, totalmente no tradicional, que se demostró en la práctica como conformador de un habitat adecuado para la movilización de capital social y cultura, y para la obtención de eficiencia. En los tres casos la base de ese diseño fue la participación organizada de la comunidad. Hemos analizado en detalle las posibilidades organizacionales de la participación, en un trabajo reciente (Kliksberg, 1998). Alli se señala, en base al análisis de experiencias comparadas internacionales, $y$ de amplia evidencia empírica, que la participación tiene ventajas competitivas relevantes respecto a los diseños jerárquicos usuales, y se identifican los mecanismos a través de los cuales se generan dichas ventajas. Por otra parte, la participación forma hoy parte central de los modelos de gerencia de las organizaciones más avanzadas existentes.

Un tercer elemento distintivo de las tres experiencias es, que tras la movilización del capital social y la cultura, y los diseños de gestión, abiertos y democráti$\cos$, hubo una concepción en términos de valores. Ello es decisivo. Sin esa concepción no hubieran podido resolverse las múltiples dificultades que derivaron del camino innovativo, y no tradicional, seguido. Esos valores sinvieron de orientación continua, al mismo tiempo motivaron poderosamente el comportamiento, y transmitieron la visión de las metas finales hacia las que se dirigían los esfuerzos, visión que actuó de inspiradora permanente.

En la región se están desarrollando otras experiencias, que se caracterizan con las marcadas especificidades de cada caso por seguir, total o parcialmente, rasgos como los delineados, y agregarles otros. Sus resultados son muy relevantes. Entre muchas otras, mencionables, se hallan: el programa EDUCO, en El Salvador, basado en la autoorganización de familias campesinas pobres para la gestión de escuelas rurales, los progra- 
mas de Vaso de Leche en Perú, el rol de comunidades indigenas organizadas, en Bolivia y Ecuador, la participación de los padres en el manejo de las escuelas en Minas Geraes, y los diversos programas identificados, y sistemáticamente documentados y evaluados, en el marco del Encuentro "Programas sociales, pobreza y participación ciudadana", realizado por el BID (1998).

Se podrá argüir, como se ha hecho, que experiencias de este orden tienen un alcance limitado. Sin embargo, la realidad muestra que, si bien encuentran dificultades considerables, y no son extensibles con facilidad, hacen aportes formidables: mejoran directamente la calidad de vida de amplios sectores desfavorecidos, son un laboratorio de formas sociales avanzadas, e implican un llamado motivante a avanzar en esa dirección

En definitiva, es posible extraer de todos estos programas la respuesta a la pregunta que se planteaba al final de la sección anterior de este trabajo. Movilizar el capital social y la cultura, como agentes activos del desarrollo económico y social, no constituye una propuesta deseable, pero añadible a otras utopias, es viable, da resultados efectivos. Hay referencias significativas en las que apoyarse. Llevar a cabo esa movilización en escala considerable, gran desafío hacia el futuro, requeríá de políticas orgánicas, y de amplias concertaciones entre estado y sociedad civil. En la ultima sección de este trabajo se reflexiona sobre algunas posibles líneas de acción en el campo de potenciar la cultura para el desarrollo.

\section{Hora de movilizar el potencial de la cultura}

La actividad cultural ha sido vista con frecuencia, desde la economía, como un campo secundario ajeno a la vía central por la que debe tratarse de hacer avanzar el crecimiento económico. Ha sido con frecuencia tratada de hecho como un área que insume recursos, que no genera retornos sobre la inversión, funcionales económicamente, que es de dificil medición, y cuya gerencia es de dudosa calidad. A su vez también ha existido, desde el terreno de la cultura, una cierta tendencia al autoencierro, $\sin$ buscar activamente conexiones con los programas económicos y sociales. Todo ello ha creado una brecha considerable entre cultura y desarrollo. Ese estado de situa ción significa pérdidas considerables para la sociedad. Obstaculiza seriamente el avance de la cultura, que pasa a ser tratada como un campo secundario, y de "puro gasto" y, al mismo tiempo, tiene un gran "costo de oportunidad", no emplea sus posibles aportes a los procesos de desarrollo.

Deben emprenderse esfuerzos sistemáticos para superar la brecha causante de estas pérdidas. Como se ha visto en las secciones anteriores, la cultura constituye parte relevante del capital social, es portadora de múltiples posibilidades de contribución a las acciones del desarrollo, y ello no es teorización, como lo han indicado las experiencias reseñadas, y otras muchas en curso. La crisis del pensamiento económico convencional abre 
una "oportunidad" para que, en la búsqueda de un pensamiento más comprensivo e integral del desarrollo, se incorporen en plena legitimidad las dimensiones culturales del mismo.

Antes de explorar algunas de las intersecciones posibles, una advertencia de fondo. La cultura puede ser un instrumento formidable de progreso económico y social. Sin embargo, allí no se agota su identidad. No es un mero instrumento. El desarrollo cultural es un fin en sí mismo de las sociedades. Avanzar en este campo significa enriquecer espiritual e históricamente a una sociedad, y a sus individuos. Como lo subraya el Informe de la Cumisión Mundial de Cultura y Desarrollo de la UNESCO (1996): "es un fin deseable en sí mismo porque da sentido a nuestra existencia". Esa perspectiva no debe perderse. Una reconocida economista, Françoise Benhamou (1997), hace al respecto prevenciones a ser atendidas. Señala: "En realidad, sólo en áreas de un economicismo a ultranza, se puede pretender justificar el gasto cultural en función de los recursos tangibles que este puede generar como contrapartida. Las ganancias que la vida cultural le puede aportar a la colectividad, no siempre cubren los gastos ocasionados. Evidentemente, el interés de estos gastos debe ser evaluado en función de otros criterios, que van mas allá de la dimensión económica".

Benhamou reclama criterios diferentes para medir el "rendimiento"de algo que es, en definitiva, uno de los fines últimos de la sociedad. Advierte sobre la aplicación mecánica de criterios usualmente empleados en el campo económi$c o, y$ las consecuencias "fáciles" y erra- das que pueden extraerse de ellos. Destaca: "Sería lamentable que en momentos en que las ciencias de la economía reconocen el valor de la dimensión cualitativa del objeto que están evaluando, los economistas se empeñen en tomar en cuenta solamente las repercusiones comerciales de la inversión cultural. ¿Hay que quejarse del costo de la vida cultural que, en definitiva, es realmente modesto? ¿No habrá que ver en él, el símbolo de una nación adulta y próspera?"

Junto a ser un fin en sí misma la cultura tiene amplísimos potenciales a movilizar para el desarrollo. Entre ellos se hallan los que se presentan, sumariamente, a continuación.

\subsection{Cultura y políticas sociales}

La movilización cultural puede ser de gran relevancia para la lucha contra la pobreza que hoy aflige, a través de diversas expresiones, a cerca de la mitad de la población de la región. Los elementos "intangibles" subyacentes en la cultura pueden cooperar de múltiples modos.

Los grupos pobres no tienen riquezas materiales pero tienen un bagaje cultural, en oportunidades, como sucede con las poblaciones indígenas, de siglos o milenios. El respeto profundo por su cultura creará condiciones favorables para la utilización, en el marco de los programas sociales, de saberes acumulados, tradiciones, modos de vincularse con la naturaleza, capacidades culturales naturales para la autoorganización, que pueden ser de alta utilidad.

Por otra parte, la consideración y valoración de la cultura de los sectores 
desfavorecidos, es un punto clave para el crucial tema de la identidad colectiva y la autoestima. Con frecuencia la marginalidad y la pobreza económicas son acompañadas por desvalorizaciones culturales. La cultura de los pobres es estigmatizada por sectores de la sociedad como inferior, precaria, atrasada. Se adjudican incluso, "alegremente", a pautas de esa cultura las razones mismas de la pobreza. Los pobres sienten que, además de sus dificultades materiales, hay un proceso silencioso de "desprecio cultural" hacia sus valores, tradiciones, saberes, formas de relación. Al desvalorizar la cuitura, se está en definitiva debilitando la identidad. Una identidad golpeada genera sentimientos colectivos e individuales de baja autoestima.

Las políticas sociales deberían tener como un objetivo relevante la reversión de este proceso y la elevación de la autoestima grupal y personal de las poblaciones desfavorecidas. Una autoestima fortalecida puede ser un potente motor de construcción y creatividad. La mediación imprescindible es la cultura. La promoción de la cultura popular, la apertura de canales para su expresión, su cultivo en las generaciones jóvenes, la creación de un clima de aprecio genuino por sus contenidos, hará crecer la cultura y, con ello, devolverá identidad a los grupos empobrecidos.

En América Latina hay interesantes experiencias de este orden. Entre ellas, la pujante acción de formación de coros populares y conjuntos musicales, realizada en Venezuela en las últimas décadas. Por vía de un trabajo sostenido se conformaron en distintas comunidades, muchas de ellas pobres, conjuntos que aglutinaron a miles de niños y jóvenes en derredor, principalmente, de temas de la cultura popular. Estos espacios culturales, al mismo tiempo que permitían expresarse y crecer artísticamente a sus miembros, les transmitian amor y valoración por su cultura, y fortalecían su identidad. Asimismo, tenian efectos no previstos. La práctica sistemática de estas actividades fomentaba, de hecho, hábitos de disciplina, culto por el trabajo y cooperación. Similares experiencias se realizaron en gran escala en períodos recientes en Colombia, y en otros paises.

\subsection{Cultura e integración social}

Uno de los problemas básicos de las sociedades latinoamericanas es la exclusión social. Ella implica dificultades severas para acceder a los mercados de trabajo y de consumo, pero junto a ellas, imposibilidad de integración a marcos de la sociedad. Unos factores se refuerzan a otros, configurando círculos perversos regresivos.

La democratización de la cultura puede romper estos círculos en un aspecto relevante. La creación de espacios culturales asequibles a los sectores desfavorecidos, y estimulados especialmente, puede crear canales de integración inéditos.

La cultura puede, asimismo, reforzar significativamente el capital educativo de las poblaciones pobres. La región se caracteriza por altas tasas de deserción y repetición de dichas poblaciones en escuela primaria. Cerca de la mitad de los niños abandona la escuela antes de completar seis grados. Deben realizarse todos los esfuerzos para mejorar esta situa- 
ción. Pero, al mismo tiempo, las actividades culturales pueden funcionar como un parasistema educativo, que ofrezca posibilidades de formación informal, que complementen y refuercen la escuela. Un campo donde ello puede ser especialmente relevante, es en la amplia población de adultos que desertaron de la escuela en su juventud.

La cultura puede ser un marco de integración atractivo y concreto para los vastos contingentes de jóvenes latinoamericanos que se hallan actualmente fuera del mercado de trabajo y que, asimismo, no están en el sistema educativo. Constituyen, de hecho, una población muy expuesta al riesgo de la delincuencia. Los análisis sobre los fuertes avances de la criminalidad en la región, en las últimas décadas, indican que un porcentaje creciente de los delincuentes es joven y responde al perfil de desocupación y limitada educación. En los espacios culturales puede darse, a esta población, alternativas de pertenencia social y crecimiento personal.

La cultura puede realizar un aporte efectivo a la institución más básica de integración social, la familia. Investigaciones de los últimos años dan cuenta de que, junto a su decisivo rol afectivo y espiritual, la familia tiene impactos muy relevantes en muchas otras áreas. Influye fuertemente en el rendimiento educativo de los niños, en la formación de la creatividad y la criticidad, en el desarrollo de la inteligencia emocional, en la adquisición de una cultura de salud preventiva. Es, al mismo tiempo, una de las principales redes de protección social, y el marco primario fundamental de integración social.
En América Latina, ante el impacto de la pobreza, numerosas familias de las áreas humildes de la sociedad se han tensado al máximo, y han ingresado en procesos de crisis. Se estima que cerca del $30 \%$ de las familias de la región, son unidades con sólo la madre al frente. En la gran mayoría de los casos se trata de familias de escasos recursos. Asimismo, han aumentado los hijos extramatrimoniales, indicador de la renuencia de las parejas jóvenes a conformar familias estables, en muchos casos influida por las dificultades económicas para sostenerlas.

Los espacios culturales pueden ayudar a fortalecer esta institución, eje de la sociedad, y de incalculables aportes a ella. La actividad conjunta de los miembros de la familia, en dichos espacios, puede solidificar lazos. En ellos, las familias pueden encontrar estimulos, respuestas, enriquecer sus realidades, compartir experiencias con otras unidades familiares con similar problemática.

\subsection{Cultura y valores}

Se asigna a los valores de una cultura peso decisivo en el desarrollo. Se ha elaborado largamente al respecto, en años recientes, sobre el tipo de valores que han ayudado a países que han obtenido crecimiento sostenido y logros sociales significativos.

Si los valores dominantes se concentran en el individualismo, la indiferencia frente al destino del otro, la falta de responsabilidad colectiva, el desinterés por el bienestar general, la búsqueda como valor central del enriquecimiento personal, el consumismo, y otros seme- 
jantes, puede esperarse que estas conductas debilitaran seriamente el tejido social y pueden conducir a todo orden de impactos regresivos. Ellos pueden ir desde fuerte inequidades económicas que, según indican múltiples investigaciones, generan poderosas trabas a un desarrollo económico sostenido hasta, como ya se mencionó, descensos en la cohesión social que puede, incluso, influir negativamente sobre la esperanza de vida promedio ${ }^{2}$. Uno de los efectos visibles de la vigencia de valores antisolidarios, es la extensión de la corrupción en diversas sociedades. Como lo resalta Lourdes Arizpe (1998): "La insistencia monotemática de que enriquecerse, es lo único que vale la pena en la vida, ha contribuido en gran medida a esa tendencia".

Valores positivos conducen en direcciones diferentes. Así, por ejemplo, sociedades que han estimulado y cultivado valores favorables a la equidad, y los han reflejado en múltiples expresiones, desde sus sistemas fiscales hasta la universalización de servicios de salud, y educación de buena calidad, tienen actualmente bue- nos niveles en ese campo que, a su vez, facilitan su progreso económico y tecnológico, y su competitividad. Se mencionan con frecuencia, al respecto, casos como los de los países nórdicos, Canadá, Japón, Israel, entre otros.

La cultura es el ámbito básico donde una sociedad genera valores y los transmite generacionalmente. El trabajo en cultura en América Latina, para promover y difundir sistemáticamente valores como, la solidaridad de profundas raíces en las culturas indígenas autóctonas, la cooperación, la responsabilidad de unos por los otros, el cuidado conjunto del bienestar colectivo, la superación de las discriminaciones, la erradicación de la corrupción, actitudes pro mejoramiento de la equidad en una región tan marcadamente desigual, actitudes democráticas ${ }^{3}$, puede claramente ayudar al desarrollo además de contribuir al perfil final de la sociedad.

Son notables, al respecto, los resultados alcanzados por sociedades que han cultivado consistentemente el voluntarismo en las nuevas generaciones. La

2 Una pionera investigación sobre la incidencia de los valores en la vida cotidiana y el tejido social se halla en el sugerente trabajo del PNUD "Desarrollo Humano en Chile, 1998. Las paradojas de la modernización", PNUD, 1998. El trabajo explora el mundo interno de las personas y la calidad de sus relaciones con los otros, y realiza hallazgos de gran relevancia en términos de capital social, de cultura y de problemas de desarrollo. Identifica malestares sociales en la sociedad ligados, entre otros aspectos, al debilitamiento de las interrelaciones, la desconfianza y el temor al "otro".

3 Puede encontrarse una exploración detallada de la trascendencia de los valores culturales para el fortalecimiento de una sociedad democrática, y la necesidad de enfrentar y superar en la región actitudes culturales autoritarias, en los trabajos del Proyecto Regional Cultura y Democracia, impulsado por el Instituto de Estudios Latinoamericanos de la Universidad de Maryland, que dirige Saúl Sosnowski. 
acción voluntaria recoge muchos de los valores antes mencionados. Tiene un gran valor educativo, produce resultados económicos significativos al añadir horas de trabajo sin salario a programas relevantes para la sociedad, y es un estímulo que promueve sentimientos de solidaridad y cooperación. En diversos paises los voluntarios constituyen un porcentaje significativo de la fuerza de Irabajo total del sector social, su actividad es valorizada por toda la sociedad, y se constituye en una posibilidad que puede atraer numerosos jóvenes. Hay amplios contingentes de voluntarios en paises, como entre otros, los nórdicos, Canadá, varios países de Europa Occidental, en EE.UU. e Israel. En este último caso, Faigon (1994) indica que un $25 \%$ de la población realiza tareas voluntarias de modo regular, particularmente en el campo social, y genera bienes y servicios equivalentes al $8 \%$ del Producto Bruto Nacional. Las bases de estos resultados se hallan, según subraya, en la cultura judía que jerarquiza el servicio voluntario a la comunidad como un deber, y en la educación sistemática de valores solidarios en los marcos de la escuela israeli.

El cultivo de los valores a través de la cultura y la participación, desde los primeros años, en actividades voluntarias y en tareas comunitarias, tiene un peso considerable en la adquisición de compromisos cívicos en las edades adultas, según indican Youniss, McLellan y Yates (1997), con base en investigaciones recientes. Se observa una correlación estadística entre haber actuado en organizaciones en los años jóvenes, y el involucramiento en la sociedad en épocas posteriores. Asi, un estudio en EE.UU. evidenció, que quienes fueron miembros de clubes $4 \mathrm{H}$ tenían, 25 años después, el doble de probabilidad de estar integrando asociaciones civicas, que quienes no pasaron por ellos, y una probabilidad cuatro veces mayor, de estar participando en política. Otro estudio sobre graduados de escuelas secundarias mostró que, quince años después, los que hablan participado en actividades extracurriculares en la escuela, tenian mayor probabilidad de estar participando de asociaciones voluntarias. Los valores, y la participación, van moldeando lo que los autores llaman una "identidad cívica" orientada hacia el asumir compromisos con la comunidad, y aportar continuamente a ella.

Una interesante experiencia orientada a promover valores culturales valiosos para la sociedad, se ha iniciado hace poco en Noruega. El 30 de enero de 1998 dicho país estableció la Comisión Gubernamental de Valores Humanos. Tiene por finalidades centrales: a) crear en la sociedad una conciencia creciente acerca de los valores y los problemas éticos; b) contribuir a un mayor conocimiento acerca del desarrollo de valores humanos en nuestra cultura contemporánea; c) identificar desafíos actuales en materia ética de la sociedad, y discutir posibles respuestas, $y d$ ) promover que los diferentes sectores de la sociedad se integren a este debate.

La Comisión está constituida por integrantes que proceden de diversos sectores sociales, y de diferentes generaciones. Sus actividades se están orientando a que el tema de los valores esté en el centro de la agenda pública, sea discu- 
tido por las instituciones tanto públicas como privadas, se identifiquen y expliciten los dilemas éticos, y se busquen respuestas para ellos. Entre las primeras iniciativas que puso en marcha, se halla la de que todas las escuelas del país discutan acerca de cómo los derechos proclamados en la Declaración de Derechos Humanos de la ONU, se están aplicando en el ámbito local. También está impulsando estudios al nivel municipal, en el que descentralizará muchas de sus acciones, sobre las tensiones que niños y jóvenes sufren entre los valores con frecuencia contradictorios que reciben en el hogar, la escuela y la iglesia, en relación a los que les llegan por los medios masivos. Otro proyecto está destinado a aumentar el grado de conciencia en relación a la responsabilidad, la solidaridad, y la participación. Uno de los proyectos invitó a los Alcaldes de los Municipios del país a iniciar un proceso deliberativo en el ámbito local, para contestar la cuestión: cuáles son los rasgos básicos de una buena comunidad local.

En la movilización de las potencialidades culturales de América Latina, una región con inmensas posibilidades en este campo, como lo evidencia su fecundidad en tantos campos artísticos, se hallan importantes posibilidades de aporte a campos tan fundamentales como los presentados: lucha contra la pobreza, desarrollo de la integración social, fortalecimiento de valores comunitarios, solidarios y participativos. Dicha movilización requiere de una acción concertada entre el Estado y las organizaciones de la sociedad civil. Ambos deben coordinar estrechamente esfuerzos, aportar lo mejor que cada uno pueda contribuir para, en conjunto, liberar las ingentes fuerzas populares de creatividad cultural latentes en la región, y reforzar su legado de valores positivos.

Hay serias falencias en América Latina en esta materia. Junto a grandes esfuerzos de algunos sectores por avanzar la cultura e importantes concreciones, se observan reservas y marginaciones por parte de otros en incorporar la cultura a la agenda central del desarrollo. Se le restan recursos, se la hace objeto preferencial de recortes presupuestarios, se la somete a continuos cambios sin permitir la estabilidad necesaria para asentar actividades e instituciones. Se argumenta, asimismo, con frecuencia, que se trataría de una especie de necesidad secundaria que tendría su lugar cuando otras previas se hubieran satisfecho. Se llega, en algunos casos, a la situación tan bien descripta por Pierre Bourdieu (citado por Benhamorow, 1996): "... la ausencia de cultura se acompaña, generalmente, de la ausencia del sentimiento de esta ausencia".

Estos razonamientos y prácticas están dejando de utilizar una de las grandes fuerzas que pueden hacer cambios profundos en las realidades de un Continente, con tan difíciles desafíos abiertos en campos decisivos en la vida cotidiana de las personas, como la po- 
breza y la inequidad ${ }^{4}$. Ha llegado la hora de superarlas y explorar activamente los múttiples aportes que la cultura puede hacer al desarrollo.

\section{Bibliografía citada}

Alessina A. y Roberto Perotti (1994). The political economy of growth: a critical survey of the recent literature. The World Bank Economic Review, vol.8, No.3, pp. 351-371.

Arizpe, Lourdes (1998). La cultura como contexto del desarrollo. En Emmerij L. y Del Nuñez del Arco J (comp.). El desarrollo económico y social en los umbrales del siglo XXI, pp. 191-197. Banco Interamericano de Desarrollo, Washington, DC.

Baas, Stephan (1997). Participatory institutional development. Conference on Sustainable Agriculture and Sand Control in Gansu Desert Area.

Benhamou, Francoise (1997). Economía de la cultura. Ediciones Trilce, Uruguay.

Banco Interamericano de Desarrollo (1997) "Libro de Consulta sobre Participación".

Banco Interamericano de Desarrollo (1998) sintas sociales, pobreza y participación ciudadana". Seminario previo a la Asamblea del BID de Cartagena
Bruni Celli, Josefina (1996). Las ferias de consumo familiar de Barquisimieto (Mimeo), Caracas.

Bullen, Paul and Onyx, Jenny (1998). Measuring social capital in five communities in NSW, Center for Australian Community Organizations and Management (CACOM) Working Paper Series (No 41), University of Technology, Sydney.

Chang, Hedy Nai-Lin (1997). Democracy, diversity and social capital. National Civic Review, Summer, 1997. Vol. 86 , No.2, pp. 141-147.

Coleman, James (1990). Foundations of social theory. Harvard University Press.

Delgado Bello, Luis (1998). 20 puntos de felicidad. El Universal, 10 de diciembre, Caracas.

Faigon, Yeoschua (1994). El voluntarismo en la sociedad israeli. Documentos del Encuentro BID - Congreso Judío Latinoamericano. "La lucha contra la pobreza a fines del siglo XX", Washington DC

Ferias de Consumo Famillar de Barquisimeto (1996) (Mimeo) Venezuela.

Franco, Carlos (1992) Imágenes de Villa $E$ I Salvador. En Bernardo Kliksberg (comp.) ¿Cómo enfrentar la pobreza? Aportes para la acción, pp. 199-224, Grupo Editor Latinoamericano.

Pueden hallarse varios trabajos recientes sobre las nuevas formas de la pobreza en América Latina en B. Kliksberg (1997) (comp.), "Pobreza. Un tema impostergable. Nuevas respuestas a nivel mundial", Fondo de Cultura Económica. Entre ellos: B. Kliksberg "¿Cómo enfrentar los déficits sociales de América Latina?"; Alberto Minujín, "Estrujados. La clase media en América Latina"; José Weinstein, "Desintegración y violencia urbana". El autor explora detalladamente el tema de la inequidad en B. Kliksberg (1999), "Desigualdad y desarrollo en América Latina. El debate postergado". Reforma y Democracia. Revista del CLAD. 
Fuentes, Mario Luis (1998). Chiapas: el capital social perdido (Mimeo), México.

Gómez Calcaño, Luis (1998). Las ferias de consumos familiar del Estado Lara, Venezuela. Una experiencia de organización participativa. Seminario "Programas sociales, pobreza y par"ticipación ciudadana", BID, Cartagena.

Hagan, J., MacMillan, R. and Wheaton, B (1996). New kid in town: social capital and the life course effects of family migration on children. American Sociological Aeview, (June), pp. 368-385.

Hirschman, Alberto O. (1984). "Against parsimony: three easy ways of complicating some categories of economic discurse". American Economic Review, V. 74, N. 2, May, pp. 89-96.

Iglesias, Enrique V. (1997). Cultura, educación y desarrollo. Exposición en ocasión de la Asamblea General de la Unesco, París.

Iglesias, Enrique V. (1998). Prefacio a Emmerij L. y Nuñez del Arco, J. (comp.). El desarrollo económico y social en los umbrales del Siglo $\mathbf{X X I}$, pp. VII-XI. Banco Interamericano de Desarrollo, Washington, DC.

Jonsson Jan O. and Gahter, Michael (1997). Family dissolution, family reconstitution, and children's educational careers: recent evidence of Sweden. Demography, (May), Vol. 34, No.2, pp. 277-393.

Joseph, James (1998). Democracy's social capital: civil society in a new era. Address, January 15.

Kawachi, 1., Kennedy, B. and Lochner, K. (1997). Long Live Community. Social Capital as Public Health. The American Prospect. (November-December), pp. 56-59.
Katzman, Ruben (1997). Marginalidad e integración social en el Uruguay. Revista de la Cepal, No.62, Agosto (LC/G.1969-P), pp. 93-119. Santiago.

Kllksberg, Bernardo (1998). Seis tesis no convencionales sobre participación. Revista Venezolana de Gerencia, Año 3, No, 6, pp. 175-203. Universidad del Zulia. Maracaibo, Venezuela.

Knack, Stephan and Philip Keefer (1997). Does social capital have an economic payoff? A cross country investigation. Quarterly Journal of Economics, November. Vol. 112 No.4, pp. 12511288.

La Porta, $\mathbf{A}_{\text {, }}$ Lopez de Silanes, F., Shleifer, A. and Vishny, R. (1997). Trust in large organizations. American Economic Association papers and proceedings, May, pp. 333-338.

Levi, Margaret (1996). Social and unsocial capital: a review essay of Robert Putnam's "Making democracy work", Politics \& Society, (March), pp. 45-55.

Machado, Gustavo y Freitez, Nelson (1994). Experiencias exitosas de gestión social en Lara. En B. Kliksberg (comp.) El Desarrollo Humano en Venezuela PNVO, Editorial Monte Avlla, pp. 321-326.

Migdley, James (1995). The development perspective in social welfare. Sage Publications.

Morin, Edgard (1991). Un noveau commencement. Editions du Seuil. Francia.

Navarro, Zander (1998). La democracia afirmativa y el desarrollo redistributivo: el caso del presupuesto participativo en Porto Alegre, Brasil (1989-1998). Seminario "Programas sociales, pobreza y participación ciudadana", BID, Cartagena.

Narayan, Deepa and Pritchett, Lant (1997). Cents and Sociability. Household in- 
come and social capital in rural Tanzania. The World Bank.

Newton, Kenneth (1997). Social capital and democracy. American Behavioral Scientist. (March-April), pp. 575-586.

Putnam, Robert (1994). Para hacer que la democracia funcione. Editorial Galac, Venezuela.

Papa Juan Pablo II (1996). Palabras en su vislta a Villa El Salvador, 5 de febrero de 1985. En: Zapata, Antonio V. Sociedad y Poder Local. La Comunidad de Villa El Salvador, 1971-1996. DESCO, pp. 333-340.

Prigogine, llya (1998). Tan sólo una ilusión. Una exploración del caos al orden. Tusquets Editores, Barcelona.

Peunión de las Américas (1998). Declaración de Santiago. Santiago de Chile.

Rupp, Jan C. (1997). Fethinking cultural and economic capital. Reworking class, pp. 221-241. Edited by John Hall, New York, Cornell University Press.

Salas, Gustavo (1991). El programa de ferias de consumo familiar: una alternativa de gestión de la economía popular en gran escala desde la organización comunitaria. Ponencla en las Jornadas Hispano-Venezolanas de Economia Popular, 12 al 14 de noviembre. Barquisimeto, Venezuela.

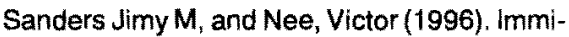
grant selt-employment: the family as social capital and the value of human capital. American Sociological Review, (April), pp. 231-249.

Sen, Amartya (1997). Economics, Business principles and moral sentiments. The Journal of the Society for Business Ethics. July, Vol, 7, No.3, pp. 5-16.

Sen, Amartya (1981). Poverty and Famines: an essay on entitlement and deprivation. Ox ford, Clarendon Press.
Sen, Amartya (1998). Teorla del desarrollo a principios del Siglo XXI. En Emmerij L. y Núñez del Arco J. (comp.). El desarrolla económico y social en los umbrales del siglo XXI, pp. 589-610. BID.

Serageldin, Ismail (1998). The initiative on defining, monitoring and measuring. social capital: overview, and program description. Social capital initiative working paper No.1, World Bank.

Stiglitz, Joseph. (abril, 1998a). Más instrumentos y metas más amplias: desde Washington hasta Santiago. Banco Mundial.

Stiglitz, Joseph (1998b). Towards a new paradigm for development: strategies, policies and processes. Prebisch Lecture, UNCTAD.

Teachman, Jay D., Paasch, Kathleen and Carver, Karen (1997). Social capital and the generation of human capital. Social Forces, June. Vol. 75, No.4, pp. 1-17.

Touraine, Alan (1997). Por una nueva politica social. El País, Madrid, 4 de agosto.

Unesco (1996). Nuestra diversidad creativa. Informe de la Comisión Mundial de Cultura y Desarrollo.

Wall, E., Ferrazzi, G. and Schryer, F. (1998). Getting the goods on social capital. Rural Sociology, Vol.63, No.2, pp 300-322.

Wickrane K.A.S, and Mulford, Charles L. (1996). Political democracy, economic development, disarticulation, and social well-being in developing countries. The Sociological Quarterly, pp. 375-390.

Wilson, J. (1994): Los valores familiares y el papel de la mujer, Facetas, No. 1, Washington, DC. 
Wolfensohn, James D. (1996). El gasto social es clave. Clarín, Buenos, 26 de febrero.

Wolfensohn, James D. (1998). La otra crisis. World Bank, Washington, DC

World Bank (1998). Beyond the Washington Consensus. Institutions Matter.
Youniss, James, McLellan, Jeffey A. and Ya. tes, Miranda (1997). What we know about engendering civic identity. American Behavioral Scientist. March/April, pp. 620 631 .

Zapata, Antonio V. (1996). Sociedad y poder local. La Comunidad de Villa EI Salvador 1971-1996. DESCO, Perú. 